\title{
La fotografía artística contemporánea en el marco de la promoción cultural. Los carteles del Centro Dramático Nacional como caso de estudio
}

Sandra Martorell Fernández | sandramartorell@uoc.edu

Universitat Oberta de Catalunya

Álvaro Sanchís Gandía | alsangan@pin.upv.es

Universitat Politècnica de València

Palabras clave

"artes escénicas"; "fotografía"; "cartel";

"comunicación persuasiva”; "cartelería teatral”.

Sumario

1. Introducción.

2. Metodología.

3. La relación entre fotografía y cartelismo.

4. Los carteles fotográficos del CDN.

4.1. Unos carteles únicos. La relación del CDN

con su público.

4.2. Bodas de sangre como caso de estudio.

4.3. Análisis del uso fotográfico y resultados.

5. Conclusiones.

6. Bibliografía.

\section{Resumen}

La capacidad comunicativa y discursiva de la fotografía es un hecho manifiesto desde su aparición a principios del siglo XIX. En la contemporaneidad, y en medio de una vorágine de millones de imágenes creadas cada día sin juicios ni miras, aún hay espacio para la imagen pensada, calma y aguda. El Centro Dramático Nacional apuesta por diseños en los que está presente este tipo de fotografía, de carácter artístico y discurrido con ingenio para presentar sus creaciones teatrales a través de carteles minimalistas y con gran carga conceptual. Una forma de acercarnos un teatro diferente que sirve a la vez como ejemplo de la interacción de varias disciplinas que unen fuerzas con el fin de destacar y diferenciarse de sus análogos gracias a un estilo propio y una sagacidad refinada que toma la semiología como pretexto de creación. Así esta propuesta pretende poner sobre la mesa el valor de repensar la imagen fotográfica aprovechando su disposición persuasiva a partir del caso en particular de los carteles del CDN con el fin de ver el papel que ocupa en ellos.

\section{Cómo citar este texto:}

Sandra Martorell Fernández, Álvaro Sanchís Gandía (2018): La fotografía artística contemporánea en el marco de la promoción cultural. Los carteles del Centro Dramático Nacional como caso de estudio, en Miguel Hernández Communication Journal, n9 (2), pp. 309 a 336. Universidad Miguel Hernández, UMH (Elche-Alicante). DOI: http://dx.doi.org/10.21134/mhcj.v0i9.259 


\section{Contemporary artistic photography within the framework of cultural promotion. Posters of the National Dramatic Center as a case study}

Sandra Martorell Fernández | sandramartorell@uoc.edu Universitat Oberta de Catalunya

Álvaro Sanchís Gandía | alsangan@pin.upv.es

Universitat Politècnica de València

Keywords

"Performing Arts"; "Photography"; "Poster"; "Persuasive communication"; "Stagy Posters".

Summary

1. Introduction.

2. Methodology.

3. The relationship between photography and poster design.

4. The CDN photographic posters.

4.1. Some outstanding posters. The relationship

between the CDN and its audience.

4.2. Bodas de sangre as a case study.

4.3. Analysis of photographic use and results.

5. Conclusions.

6. Bibliography.

\section{Abstract}

It's clear the communicative and discursive capacities of photography since its discovery at the beginning of the 19th century. Nowadays (in the midst of a maelstrom of millions of images created every day without judgments or sights) there is still a place for an image thought, calm and smart. The National Dramatic Center bets for designs in which this type of photography is present: artistic images designed with ingenuity to present its theatrical creations through minimalist posters and with a great conceptual load. A way to approach a different theater that serves as an example of the interaction of several disciplines, that join forces in order to stand out; and also to differentiate from their analogues because of their own style and a refined sagacity that takes semiology as a pretext for creation. So this proposal aims to expose the value of rethinking the photographic image taking advantage of its persuasive disposition from the case of the CDN posters.

\section{How to cite this text:}

Sandra Martorell Fernández, Álvaro Sanchís Gandía (2018): Contemporary artistic photography within the framework of cultural promotion. Posters of the National Dramatic Center as a case study, in Miguel Hernández Communication Journal, nº (2), pp. 309 a 336. Universidad Miguel Hernández, UMH (ElcheAlicante). DOI: http://dx.doi.org/10.21134/mhcj.v0i9.259 


\section{Introducción}

Según Photoworld (2015), nos llevaría diez años ver las fotos compartidas en Snapchat en la última hora; a razón de 8.796 fotos de media por segundo - y esto solo en Snapchat- A esto habría que sumar las que compartimos a través de Whatsapp, Facebook, Instagram, Flickr y tantas otras redes y, además, las que tomamos pero no compartimos. Indudablemente vivimos en una imagosfera en que la imagen es uno de los elementos centrales de la comunicación interpersonal. Hace ya un lustro, Samsung publicaba que, solo en España, la cantidad de imágenes compartidas por día era de 7,5 millones (Calatrava, 2013).

Esta cifra ha ido en aumento por la cada vez mayor familiaridad de uso con los teléfonos inteligentes que facilitan la captura y compartición de fotografías a través de aplicaciones incluso en grupos sociales antes más distantes debido a cuestiones de alfabetización digital-, el abaratamiento de los dispositivos — aunque no sea especialmente notorio- y el crecimiento de ventas de los mismos, que ha ido subiendo progresivamente según datos de la consultora IDC (Álvarez del Vayo, 2017). Esto en lo que refiere a imágenes compartidas por usuarios, a las cuales cabe que sumar los tres mil impactos publicitarios que recibimos diariamente (Zenith Media, 2015).

Ante tal cantidad ingente de fotografías conseguir captar la atención del público es especialmente complejo. Tenemos que lidiar con el trabajo de grandes equipos creativos, con el ego y el voyerismo de millones de usuarios y con una mirada cada vez más avezada a la lluvia de imágenes que hace más ardua la tarea de sorprender y hacerse un hueco en el mar de emociones del espectador. No obstante, a pesar de todo, la fotografía sigue siendo protagonista y con el desafío crece el entusiasmo; el mismo que se manifestó en el siglo XIX con la primera imagen fotográfica.

Han cambiado los medios, pero no el anhelo de sobresalir y emocionar. Así ocurre también en otras artes y disciplinas creativas como la literatura, la danza o el teatro, con las que a menudo trabaja la fotografía. En el caso de las artes escénicas un punto de encuentro es el cartel publicitario en el que, a través de la imagen, se intenta mostrar la esencia de la obra con el objetivo final de la persuasión asociada, en última instancia, a conseguir atraer mayor número de público:

El cartel nos propone una frase, un tema, una afirmación, una evocación poética, tan arraigados en nuestra actividad diaria, que sólo la enunciación en palabras de su mensaje hace resaltar su banalidad; y sin embargo, a través de este conjunto de vulgaridades se crea una trama sutil de motivaciones, infinitamente complicada y delicada, que hace del trabajo del cartelista uno de los más penetrantes de toda la retórica (Enel, 1977: 12).

Un ejemplo de combinación de disciplinas a través de la cartelería es el Centro Dramático Nacional que aúna las artes escénicas con otras tales como el diseño gráfico, la literatura y la fotografía. Por ello hemos querido centrar la presente propuesta en esta institución y sus políticas de colaboración y complementación artística — que la han llevado a posicionarse como un referente indispensable en cuanto a comunicación de su programación-, concretamente en su propuesta de cartelismo que lleva ofreciendo desde los últimos doce años.

Nuestros objetivos en este análisis parten de la puesta en valor del trabajo realizado desde este centro, resuelto mediante una comunicación visual potente, identificable y significante. Son 
fundamentalmente los siguientes: repensar la imagen fotográfica como herramienta creativa; conocer el papel de la fotografía en los carteles de promoción cultural y especialmente en los del CDN; ver la relación entre los carteles que usan la imagen fotográfica respecto a los que no; y por último, conocer la relación entre el creador gráfico y el dramaturgo.

Para tales objetivos, analizaremos la evolución de las distintas temporadas producidas por el centro, poniendo especial énfasis en aquellas que usan la fotografía a la hora de elaborar estos carteles. En este sentido, podemos decir que el medio fotográfico es una de las herramientas de mayor alcance para la consecución de imágenes de impacto — aspecto que los diseñadores de cada temporada del CDN han sabido utilizar a su favor, existiendo una destacada presencia de carteles basados en la fotografía en la colección del centro-. Además, profundizaremos en los recursos visuales y narrativos utilizados para conseguir otorgar a los objetos fotografiados una nueva semántica, aspecto que les convierte en unidades comunicativas de gran alcance en consonancia con el texto teatral representado.

\section{Metodología}

Para conseguir dar respuesta a los objetivos planteados, iniciamos nuestra investigación llevando a cabo un inventario de los carteles producidos por el CDN en los últimos doce años ${ }^{1}$. A partir de éstos estudiamos su evolución y los clasificamos atendiendo a la técnica predominante en su construcción: fotografía, dibujo, texto, etc. En segundo lugar, llevamos a cabo una serie de entrevistas en profundidad a personalidades de interés, tanto del ámbito de la gestión y dirección del centro como a artistas. Los primeros como agentes clave en la toma de decisiones y los segundos como artífices creativos. Además, realizamos una revisión de la literatura relacionada así como un análisis de referentes y precursores destacados para comprender el alcance de este uso fotográfico y sus implicaciones.

\section{La relación entre fotografía y cartelismo}

Desde sus orígenes a mediados del siglo XIX, el cartel ha sido un formato intrínsecamente vinculado tanto a la función comunicativa como a los medios técnicos disponibles para materializar su producción. En primer lugar, debido a que las necesidades comunicativas propias de la época dieron lugar al nacimiento del formato y a su característica combinación de imagen y texto. En segundo lugar, por la evolución de sistemas de reproducción como la xilografía, la litografía o la imprenta moderna, que han determinado drásticamente su lenguaje visual y los recursos utilizados en su composición (Heras, 2012: 155). Se trata pues de un medio directamente relacionado con los movimientos y tendencias artísticas de cada época, especialmente con las vanguardias del siglo XX y con la fotografía (Barnicoat, 2000).

El cartel es un formato especialmente flexible y polivalente, aspectos que han propiciado su adaptación a infinidad de usos. Fue desde sus inicios un medio que tuvo gran difusión en el ámbito de las artes escénicas, así como la gráfica publicitaria. Además, su uso político fue especialmente destacado en las grandes guerras así como en el conflicto civil español, con figuras destacadas como Josep Renau o Vicente Ballester (Tomás, 2006). Durante el siglo XX, el cartel se consolidó como un medio de comunicación directo, eficaz y especialmente cercano con todos los núcleos de población (Renau, 1976: 14). En los diferentes ámbitos donde se ha desarrollado este medio y en sus diferentes técnicas, encontramos factores comunes que lo caracterizan: la relación entre imagen y texto siempre está presente, siendo el uso de la tipografía un factor fundamental para conseguir la cohesión necesaria.

${ }^{1}$ En el año 2006 se dio un giro a los carteles del CDN con una nueva apuesta gráfica. 
Esta imagen principal se caracteriza por su contundencia e iconicidad, predominando la síntesis como proceso fundamental para la obtención de composiciones de impacto. Tras el nacimiento de la fotografía y su posterior popularización, multitud de artistas se acercaron a esta técnica para experimentar con sus posibilidades. Son especialmente notorios los collages visuales generados por Man Ray en 1921, donde la unión de diferentes partes de objetos dotaba a estos de nuevos significados (fig. 1). La aplicación al formato cartel de este tipo de imagen estuvo vinculada al movimiento Dadaísta alrededor de 1916, que encontró en la fotografía un excelente modo de conseguir imágenes pregnantes que pudieran funcionar dentro de piezas artísticas y carteles.

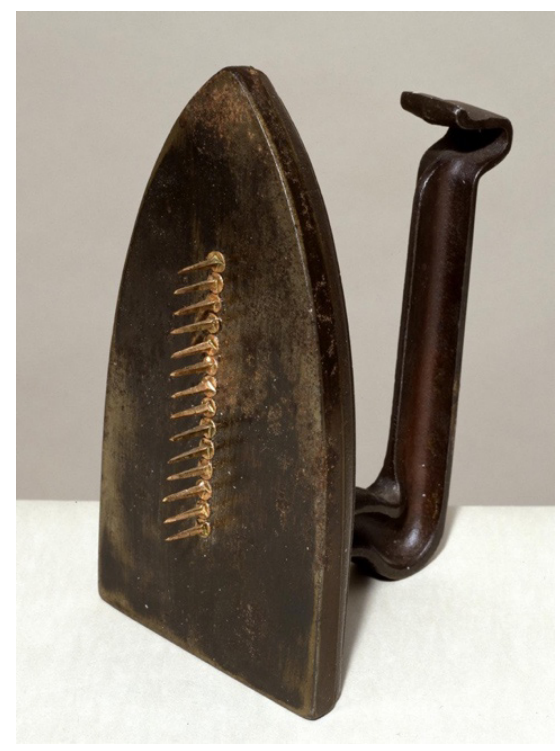

Figura 1. Regalo. Man Ray, 1921, replica de 1972. Fuente: Tate Gallery. https://goo.gl/WYpoZ1

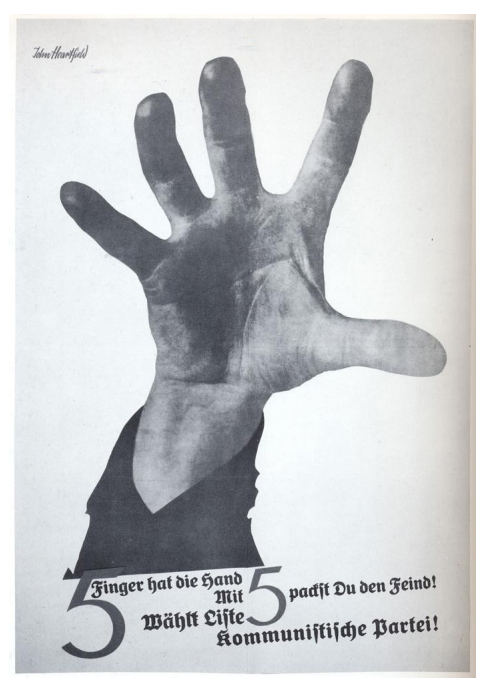

Figura 2. Die rote fahne. John Heartfield (1928). Fuente: https://goo.gl/4p9hBS 
Artistas como John Heartfield combinaron imagen fotográfica a modo de recorte o collage con tipografía para crear carteles llamativos con una clara voluntad política, consolidando la fotografía como medio válido dentro de este ámbito (fig. 2).

Simultáneamente, los hermanos Vladimir y Georgii Stenberg utilizaron la fotografía dentro de composiciones más complejas en carteles vinculados al cine ruso. Su trabajo de collage y ensamblaje combina el tratamiento cromático a favor del dramatismo del resultado final (fig. 3). Estos casos pioneros anticipan lo que posteriormente se convertirá en un recurso consolidado, uniendo la fotografía y el cartelismo en infinidad de ámbitos.

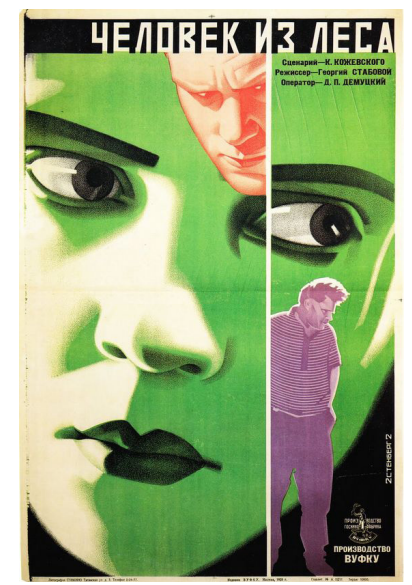

Figura 3. The man from the forest. Vladimir y Georgii Stenberg (1928). Fuente: https://goo.gl/JS9GjU

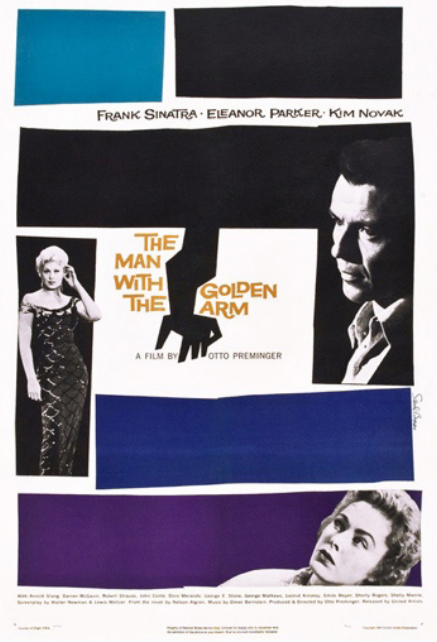

Figura 4. Saul Bass. Cartel para The Man with the Golden Arm (Preminger, 1960). Fuente: https:// goo.gl/YhieR1

La relación entre cartelismo y fotografía quedaría desde aquel entonces establecida y se convertiría en indivisible, en gran parte por la eficacia del medio fotográfico para conseguir imágenes de elevado impacto y pregnancia visual. Tras los grandes conflictos bélicos, el uso del cartel fotográfico se diversificó hacia ámbitos como la publicidad o el entretenimiento. En estos 
medios, la imagen captada por cámaras resultó utilizada en infinidad de ocasiones, siendo muy frecuentes la captación de escenas relacionadas con temáticas familiares, moda o productos de consumo. En el ámbito cultural, son buenos ejemplos los carteles que el diseñador Saul Bass produjo en los años 50 y 60, donde el autor combinaba su característico uso de las formas geométricas con fragmentos fotográficos. El resultado eran composiciones de elevado impacto visual que a día de hoy todavía mantienen su vigencia estética (fig. 4).

Avanzando cronológicamente y focalizando el punto de atención en la cartelería del CDN, resulta fundamental nombrar algunos antecedentes que influyeron de manera significativa a los autores que conformaron la identidad visual de este centro de producción teatral. Es inevitable nombrar el trabajo realizado en los años 70 por Daniel Gil para Alianza Editorial, donde ilustró miles de cubiertas de libros con imágenes simbólicas basadas en la fotografía ${ }^{1}$, donde los objetos toman nuevos e inquietantes significados (fig. 5 y 6). Como señala el profesor Agustín Gómez, hubo algunos ámbitos donde los diseñadores gráficos encontraron la libertad necesaria para desarrollar ampliamente su creatividad:

en la actualidad los artistas del diseño gráfico lo han revitalizado [el cartel] a través de propuestas subversivas. Para él [John Foster ${ }^{2}$ ] algunos de los más relevantes diseñadores actuales se han centrado en proyectos en los campos del teatro y la música que permitían una libertad creativa manteniendo propuestas relevantes que devolvían la importancia al cartel (Gómez. 2009: 2).
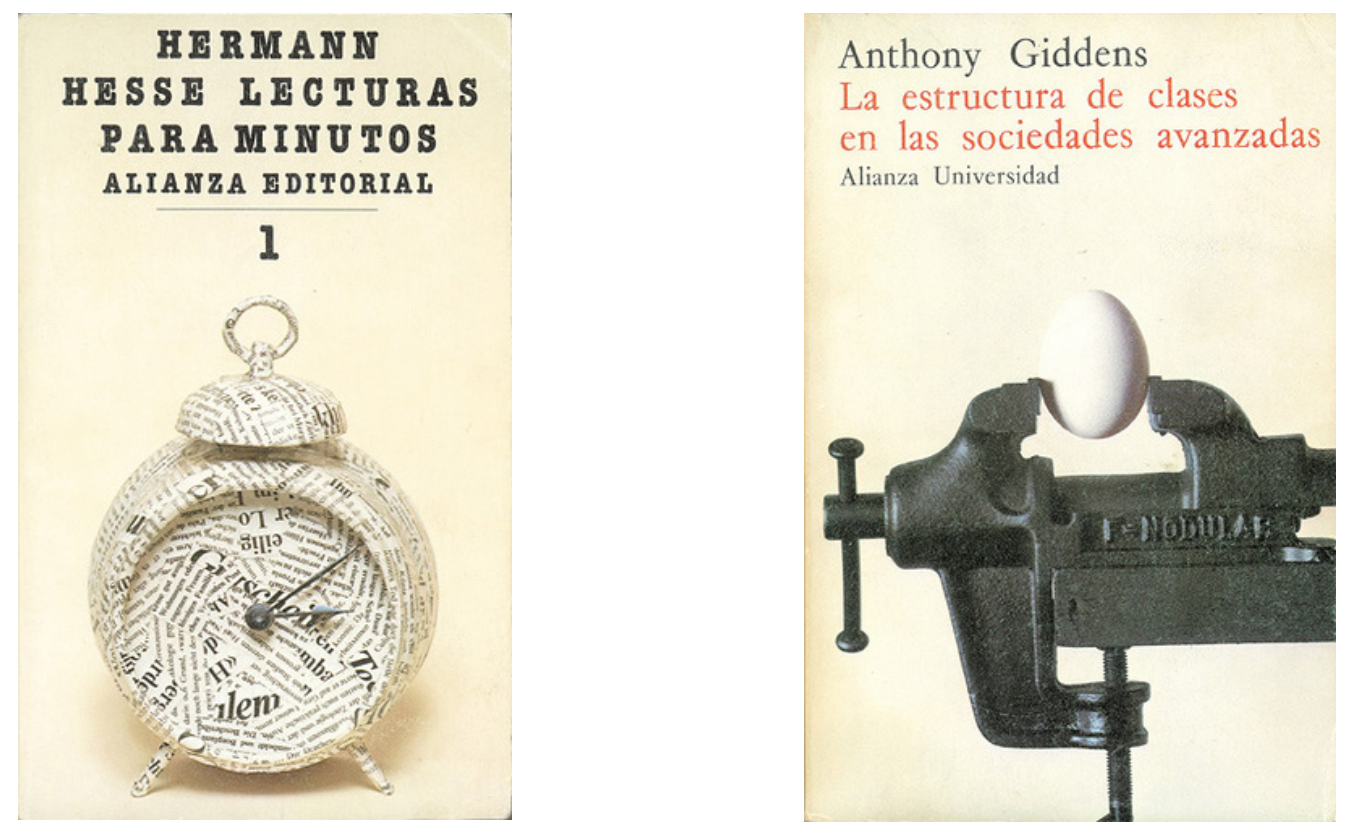

Figuras 5 y 6. Daniel Gil. Cubiertas para Alianza Editorial colección El libro de bolsillo (1975 y 1978).

Además, el trabajo de artistas como Joan Brossa (fig. 7) o Chema Madoz (fig. 8) combinan de manera magistral la suma de significados que tan frecuentemente encontraremos en la cartelería del CDN.

${ }^{1}$ Daniel Gil fue el autor de más de 4.000 portadas para la colección El libro de bolsillo, entre 1966 y 1992.

${ }^{2}$ Foster, J. (2006): Carteles. Nuevos diseñadores. Barcelona: Gustavo Gili. 

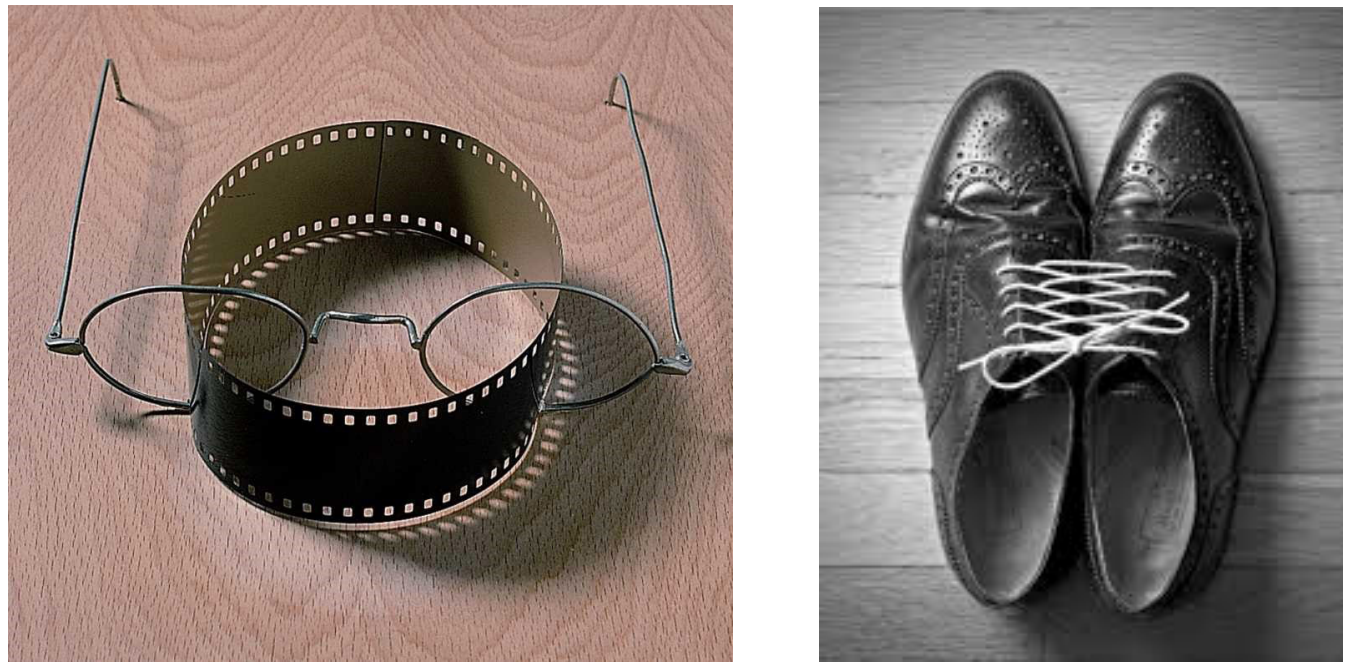

Figuras 7 y 8. Joan Brossa. Cinema (1988). Chema Madoz. Zapatos (2001).

\section{Los carteles fotográficos del CDN}

El Centro Dramático Nacional es un centro de producción y creación teatral público, dependiente del Instituto Nacional de las Artes Escénicas y de la Música, competencia del Ministerio de Educación, Cultura y Deportes. En la historia del CDN pueden distinguirse varias etapas, delimitadas por los cambios en la dirección de la institución: Adolfo Marsillach (19781979), el triunvirato formado por Nuria Espert, José Luis Gómez y Ramón Tamayo (19791981), José Luis Alonso (1981-1983), Lluís Pasqual (1983-1989), José Carlos Plaza (1989-1994), Amaya de Miguel (1994), Isabel Navarro (1994-1996), Juan Carlos Pérez de la Fuente (19962004), Gerardo Vera (2004-2011) y el actual director Ernesto Caballero desde enero de 2012.

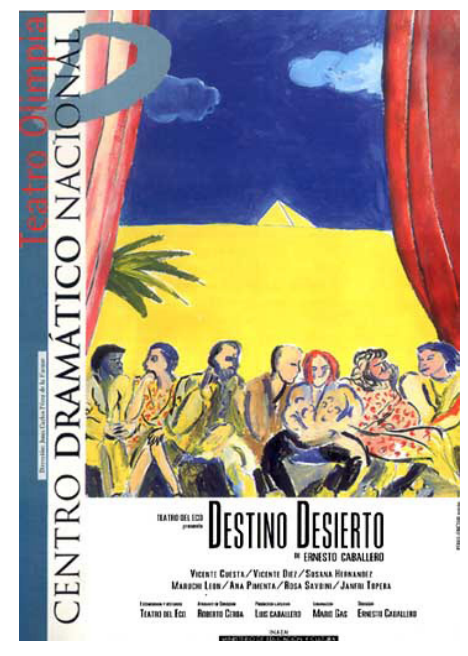

Figura 9. Cartel para Destino Desierto de Ernesto Caballero, realizado por la compañía Teatro El Cruce. 
Su propuesta teatral se caracteriza por realizar relecturas de textos desde un prisma arriesgado e innovador, reflejando este carácter en sus propuestas de comunicación gráfica, especialmente desde el año 2006 bajo la dirección de Gerardo Vera. Anteriormente a esta fecha, los carteles del CDN carecían de unidad visual. Se trata de trabajos producidos por las propias compañías y, por tanto, encontramos diversidad de lenguajes y resultados, siendo inexistente el concepto de colección entre temporadas que encontraremos posteriormente — por ejemplo, Destino Desierto de Ernesto Caballero, realizado por la compañía Teatro El Cruce (fig. 9)—.

Fue bajo la dirección de Gerardo Vera, en el año 2006, cuando la comunicación del teatro dio un notorio cambio de rumbo al profesionalizar la imagen del centro, encargando la temporada completa al diseñador Isidro Ferrer (Madrid, 1963). Este diseñador e ilustrador formado en arte dramático unificó mediante un lenguaje coherente y eficaz la cartelería de esta temporada. Sus carteles en las temporadas 2006-2007 y 2007-2008 —en las que trabajó en colaboración con Nicolás Sánchez- utilizaron siluetas como elemento gráfico principal, generando composiciones de alto contraste con escasos recursos cromáticos: fondo blanco, siluetas negras y tipografía roja o negra para añadir la capa de información necesaria.

Estas imágenes sintéticas se caracterizan por la hibridación entre elementos (objetos, animales o figuras humanas) que dotan al resultado final de una nueva semántica (fig. 10,11 y 12), remitiendo a los trabajos realizados por Daniel Gil previamente comentados (Díaz de Tuesta, 2008). Mediante el ingenio y la combinación formal, los símbolos ganan nuevas lecturas acercándose siempre a la temática principal del texto teatral representado. Este tipo de combinaciones de opuestos siempre le han fascinado:

En la lista de sus filias están también los carteles de cine hechos en Polonia en los años sesenta y setenta, "se trabajaba con la mezcla de intenciones distintas, es el juego de los contrarios, crear algo nuevo a partir de dos cosas diferentes, a veces antagónicas", explica este diseñador que ha recibido dos premios nacionales de disciplinas que para algunos son también contrarias: el de Diseño Gráfico en 2002 y el de Ilustración en 2006. (Díaz de Tuesta, 2008)
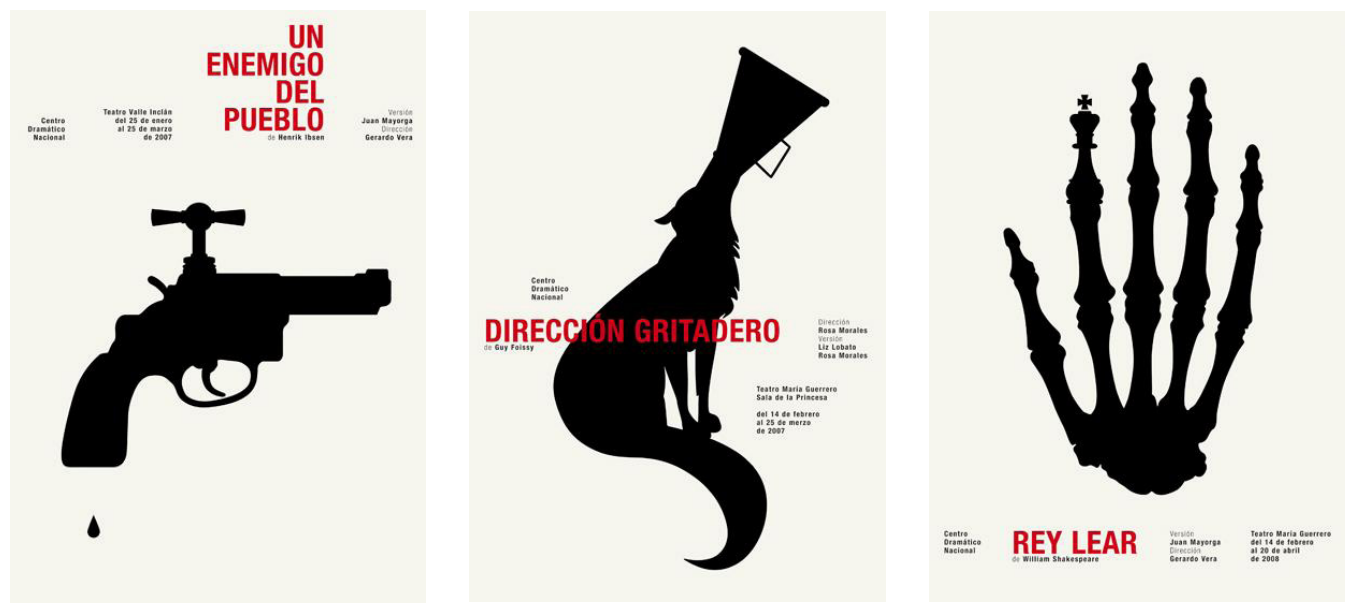

Figuras 10, 11 y 12. Isidro Ferrer. Un enemigo del pueblo (2006), Dirección gritadero (2006) El rey Lear (2007). Fuente: Isidro Ferrer, https://goo.gl/bQBYqF 
En la temporada 2008-2009 Isidro Ferrer inició una colaboración con el también ilustrador y artista Sean Mackaoui (Suiza, 1969), especializado en la creación de imágenes mediante collage a partir de recortes fotográficos. La colaboración entre ambos dio como resultado un giro al planteamiento inicial de Ferrer, al reemplazarse las siluetas por elementos fotográficos.
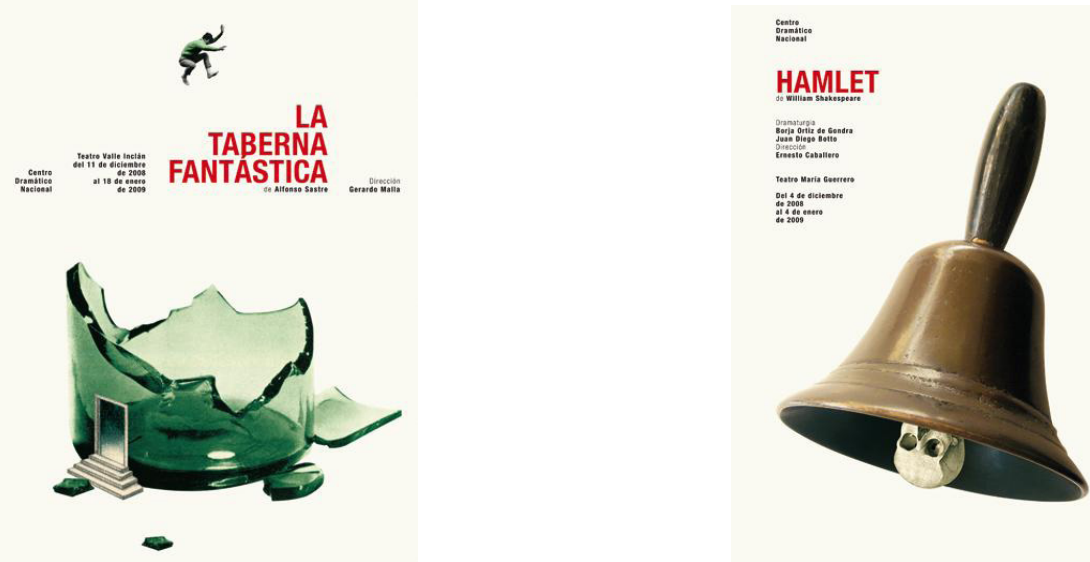

Figuras 13 y 14. Isidro Ferrer y Seaon Mackaoui. La taberna fantástica (2008) y Hamlet (2008).

Fuente: Isidro Ferrer, https://goo.gl/bQBYqF

Estos dotan a los carteles de una dimensión más cercana, aproximándolos a una cotidianeidad reconstruida (de la Calle, 2013) donde se combina la proximidad de los objetos reconocidos y la extrañeza de la combinación entre ellos. A pesar de la variedad entre las imágenes seleccionadas por los autores para ilustrar los textos teatrales, su tratamiento, composición y estructura tipográfica construyen un lenguaje coherente que dota de identidad a toda la temporada (figs. 13 y 14).
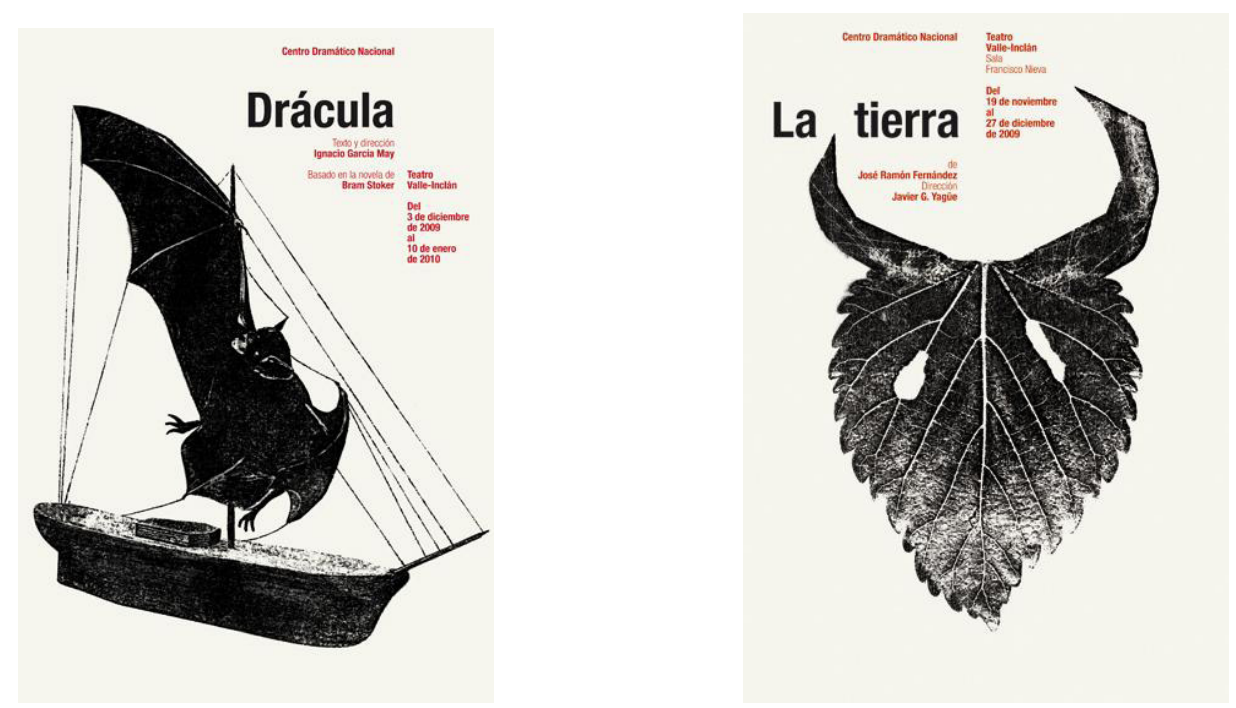

Figuras 15 y 16. Isidro Ferrer. La tierra (2009) y Drácula (2009). Fuente: Isidro Ferrer, https://goo. $\mathrm{gl} / \mathrm{bQBYqF}$ 
Si continuamos analizando la evolución de los carteles del CDN en estos primeros años tras su cambio de enfoque, encontramos en la temporada 2009-2010 un nuevo planteamiento realizado por el propio Isidro Ferrer, esta vez trabajando en solitario, donde las imágenes construidas pasan a escala de grises para conformar un lenguaje cercano a la fotografía en blanco y negro. Mediante un tratamiento que recuerda a las fotografías transferidas por la presencia de textura y grano, Ferrer consigue un lenguaje contundente que permite una vez más dotar de coherencia a los carteles diseñados para esta temporada (figs. 15 y 16). Sobre el cambio entre la temporada anterior, Isidro afirma "Sean se encargó de la parte ilustrativa y yo de lo demás. Colaboramos de forma muy estrecha pero, por el tipo de collage que hizo, todo se había dulcificado. En la cuarta temporada los carteles son míos y recuperé una línea más dura, más rotunda" (Osuna, 2011).

En la siguiente temporada (2010-2011), Ferrer abandona el proyecto y la imagen pasa a manos de Peret (Barcelona, 1945) quien cuenta con la colaboración de la fotógrafa Maria Espeus (Boras, 1969). El resultado es una temporada más heterogénea que las anteriores, donde se combinan imágenes fotográficas, recortes de ilustraciones o recursos de carácter vectorial. Una vez más, la combinación de los significados de los objetos conforma el lenguaje de los carteles, siendo la reducida paleta de colores (negro, blanco y rojo) el principal elemento cohesionador entre ellos (fig. 17 y 18). El año anterior a su colaboración con el CDN, Peret (Barcelona, 1945) ya había facturado los carteles de la temporada del Teatro del Liceo de Barcelona. "Los productores deberían recordar, entre otras cosas, que el público que asiste al teatro tiene un cierto nivel cultural y que el aserto de que una imagen vale más que mil palabras sólo es cierto que si esas mil palabras, están implícitas en la imagen.” (Osuna, 2011)
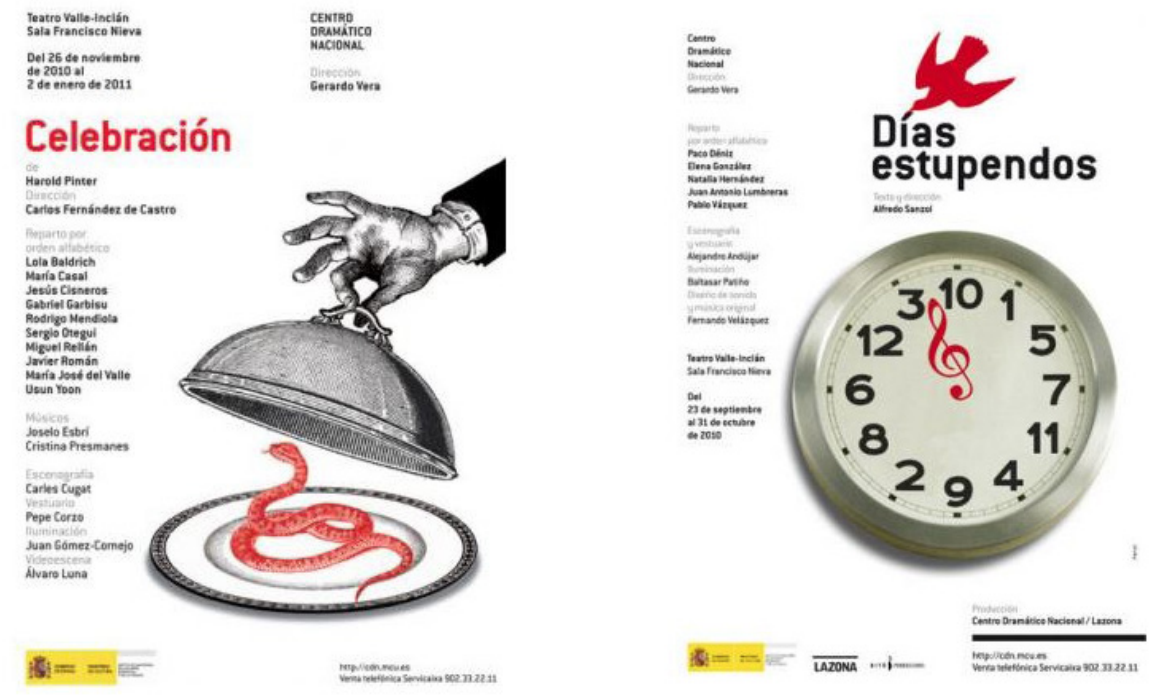

Figuras 17 y 18. Peret. Celebración (2010) y Días estupendos (2010)

Tras la pausa realizada en la temporada 2010-2011, Isidro Ferrer se reincorpora de nuevo al 
proyecto, marcando ciertas premisas desde un principio como elementos cohesionadores de la colección de carteles a diseñar. Volvemos a encontrar una clara apuesta por la fotografía, pero en esta ocasión el autor plantea un juego por el cual todos ellos mostrarán un elemento común, la máscara. Según el propio autor entrevistado por Osuna (2011): "La máscara no es solo el artilugio sobre la cara. Es la representación. Tienes que ser otro a partir de tu disfraz, el juego de las múltiples personalidades". La facilidad con la que Ferrer consigue plantear e integrar este juego durante toda la temporada resulta sorprendente (fig. 19), dotando a esta nueva serie de obras de una personalidad propia muy particular, humanizada, donde pareidolias y juegos visuales se combinan para crear distintos personajes en cada pieza de la colección.

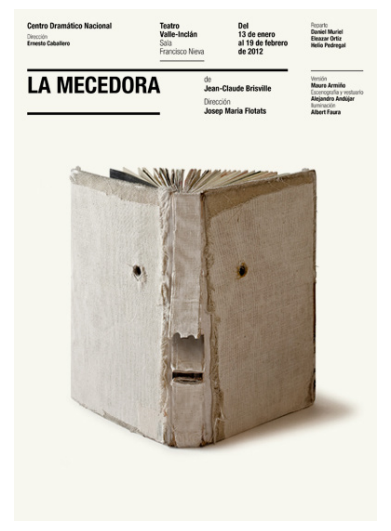

Figura 19. Isidro Ferrer. La mecedora (2011). Fuente: Isidro Ferrer, https://goo.gl/bQBYqF
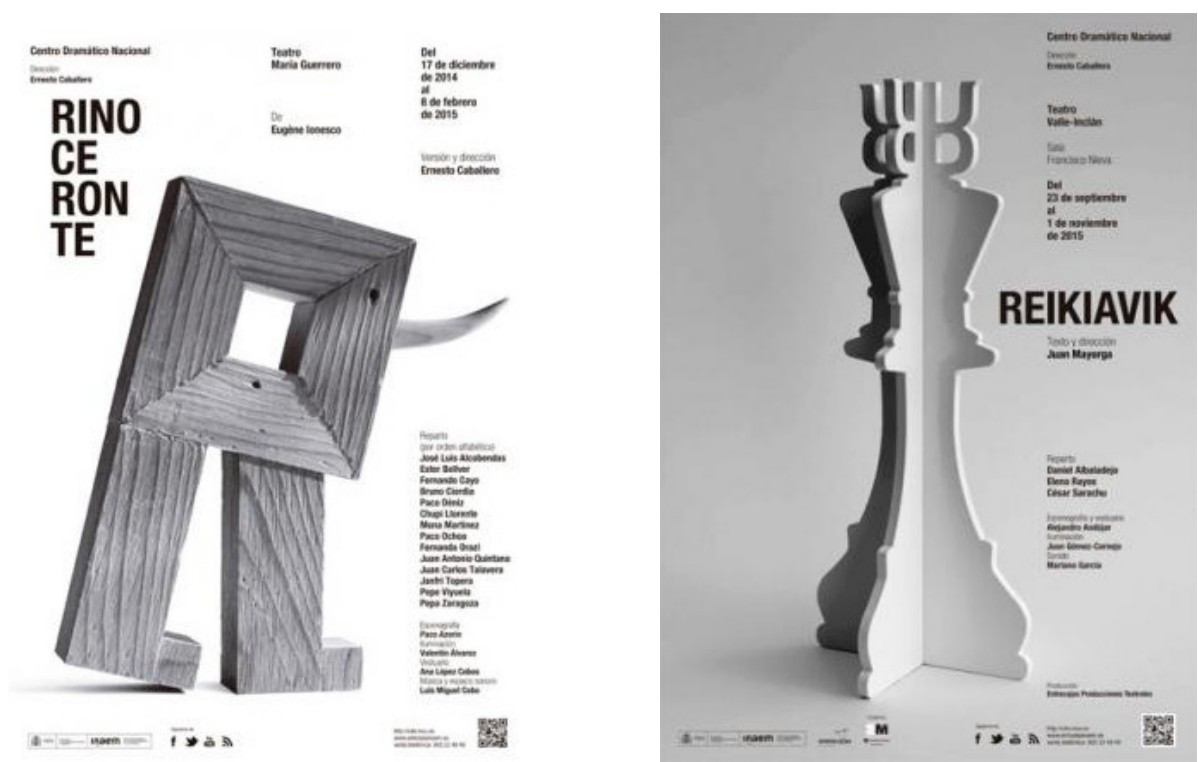

Figuras 20 y 21. Isidro Ferrer. Rinoceronte (2014) y Reikiavik (2015). Fuente: Isidro Ferrer, https:// 

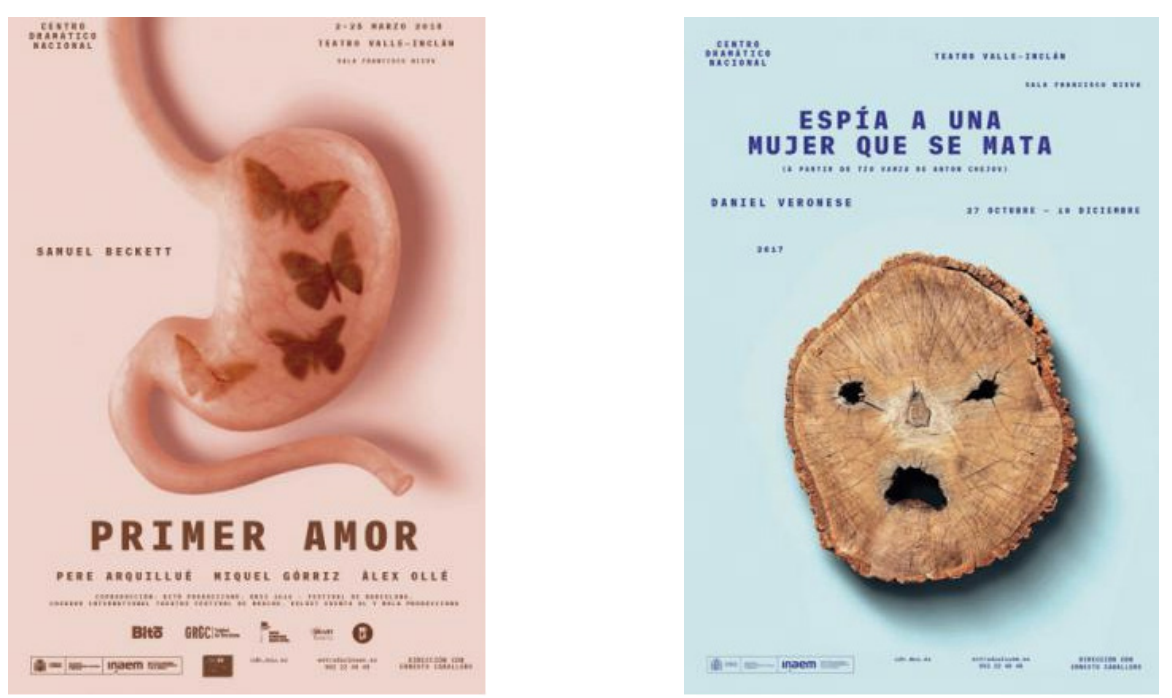

Figuras 22 y 23. Javier Jaén. Primer amor (2017) y Espía a una mujer que se mata (2017). Fuente: CDN https://goo.gl/MevTNH

$$
\text { goo.gl/bQBYqF }
$$

A partir de esta temporada, la línea fotográfica de los carteles se diluye, entrando en juego el lenguaje de la ilustración como principal elemento constructivo de la imagen (aunque con algunas excepciones, como algunas propuestas de Cecilia Molano). En las temporadas 2014-2015 y 2015-2016 (ambas de nuevo con Ferrer al frente), las imágenes están construidas mediante objetos, piezas y fragmentos de objetos que siempre evocan a representaciones tipográficas (figs. 20 y 21). Si en la temporada anteriormente analizada los elementos remiten a máscaras, en estas dos nuevas encontramos letras de gran formato, juegos tipográficos entre varias palabras u objetos que desdoblan su forma y significado para representar el texto teatral mediante su letra más representativa.

Por último, la temporada actual (2017-2018) está siendo realizada por el diseñador Javier Jaén, quien ha aportado un nuevo punto de vista en la dirección marcada por los autores anteriores. Encontramos una vez más imágenes manipuladas, metáforas visuales y objetos imposibles, pero en esta ocasión Jaén apuesta por un cromatismo diferente, marcado por la variedad de fondos de color, y por un tratamiento más directo de los objetos (figs. 22 y 23).

En ocasiones, estos objetos son fotografiados, mientras que en otras se trata de renderizaciones producidas mediante ordenador, siendo apenas imperceptible la diferencia y estando la elección de la técnica supeditada a conseguir un resultado que sorprenda y emocione al espectador. Resulta especialmente interesante esta combinación de tratamientos, pues varía sin tapujos entre las tomas fotográficas reales y las imágenes producidas digitalmente en su totalidad. En la entrevista mantenida con el propio autor, afirma con seguridad que su mayor interés radica en la dimensión narrativa de la fotografía, más allá de la técnica por la cual se obtenga la imagen. De hecho, su proceso creativo arranca con la lectura de la obra y la comprensión de la propuesta escénica mediante conversaciones con el director, para después construir una metáfora visual que como él define "a nivel conceptual, en ocasiones queda más cerca de la ilustración que de la fotografía” (Jaén, 2017). 


\subsection{Unos carteles únicos. La relación del CDN con su público}

Tras haber realizado un recorrido por el uso fotográfico en los carteles del CDN, nos preguntamos: ¿qué caracteriza a este centro para poder permitirse producir este tipo de carteles?

Resulta fácil comprender la singularidad de esta propuesta si la comparamos con el cartelismo común de infinidad de centros teatrales, donde priman recursos diametralmente distintos. En la entrevista mantenida con Ernesto Caballero, actual director del teatro, obtuvimos una respuesta clara:

[...] es un público que entiende el mensaje, que está abierto a un teatro en permanente afán renovador. Es un público excepcional, un verdadero gozo. No son meros espectadores sino que son PÚBLICO. Se trata de personas de mediana edad (cada vez hay más jóvenes), que no van una sola vez al teatro, sino que tiene continuidad. Personas con un nivel cultural medio-alto, que se caracterizan por su fidelidad, por tener un perfil más o menos especializado, gente preparada, con formación y buena predisposición para lecturas y montajes teatrales diferentes. Gente que es consumidora habitual de cultura, que no solo van al CDN (en sus dos espacios, el María Guerrero y el teatro Valle-Inclán) sino que los puedes ver también por Matadero, por Teatro Español o en un museo (Caballero, 2017).

Ernesto apostó por seguir con la línea que inició el anterior director, Gerardo Vera, que diferenciaba sus propuestas de cartel respecto de las del resto de centros. Para Caballero, el cartelismo supone un género excepcional, donde el diseñador debe convertirse en dramaturgo a través de la interpretación del texto y su conversión en una puesta en escena impresa. No es casual que varios de los diseñadores que se han vinculado al teatro hayan tenido formación teatral. En el caso de Isidro Ferrer, antes de ilustrador y diseñador gráfico estudió arte dramático y estuvo trabajando de actor.

Cecilia Molano antes de ser diseñadora gráfica y tras haber estudiado en la Real Escuela Superior de Arte dramático de Madrid (RESAD) y en la Saint Martins School of Arts de Londres, fue escenógrafa. Molano considera que su anterior trabajo en teatro no dista mucho del de diseñadora de carteles: "La filosofía es la misma al fin y al cabo. Tu tienes un texto (dramático, narrativo), y lo que buscas es una relación honesta de una escenografía 3D con la obra. Lo mismo ocurre con el diseño gráfico" (Molano, 2018). La misma opinión tiene el CDN al respecto, de ahí su denuedo a la hora de combinar el teatro con diferentes ámbitos de la cultura, como el arte gráfico o visual, la literatura o la música y, finalmente su apuesta por un diseño gráfico contundente y de vanguardia.

En este sentido la línea de carteles iniciada en el año 2006 rompe con diferentes convenciones anteriormente incuestionables dentro del cartelismo teatral: en primer lugar, llama la atención la ausencia de fotografías de los intérpretes, aspecto enormemente extendido tanto en el ámbito del teatro como por ejemplo en el cine. En segundo, destaca la exclusión en los carteles de los nombres del reparto, incluso de aquellos que podrían considerar actores estrella y que podrían suponer un gancho para atraer mayor cantidad de público. A este respecto, Caballero afirma:

Hay otros teatros, mayoritariamente de carácter privado, que han de poner en cartel al actor/actriz de turno, destacándolo/a. Esto puede darse por contrato o por cuestiones de mercadotecnia. Pero el caso del CDN es diferente, no necesita estrellas en cartel. 
Esto es posible porque es un teatro que ya tiene un público concreto y porque la marca CDN tiene mucho peso. Desde dirección consideramos que lo importante es la obra, no los actores únicamente. Así el cartel opera como manifiesto de una forma de entender el hecho teatral, sin divos, como colectivo. En ese sentido (algo que además viene auspiciado por la condición de ser una institución pública) el CDN está bastante liberado de la servidumbre, no necesita destacar a nadie (Caballero, 2018).

Nos encontramos pues ante una clara apuesta por el valor del trabajo de los diferentes especialistas en materias creativas que confluyen en el Centro Dramático Nacional. La concepción del espacio como un lugar de encuentro para las diferentes artes tiene como resultado un proyecto global estable y bien posicionado, con una base de público fiel y constante que valora los aspectos diferenciales que tan claramente identifican esta propuesta cultural.

\subsection{Bodas de Sangre como caso de estudio}

Con el objetivo de entender el punto de inflexión que supuso la cartelería del CDN respecto a otras propuestas de imagen gráfica teatral existentes, hemos tomado como caso de estudio una obra concreta — Bodas de sangre de Federico García Lorca- debido a la gran variedad de adaptaciones y planteamientos que han versado alrededor de este texto. El carácter dramático y trágico de la obra ha influido de manera notoria en sus representaciones visuales, siendo frecuente encontrar elementos comunes entre ellos: el tratamiento cromático (basado fundamentalmente en el color rojo sobre negro, gris o blanco) y el uso de fotografía tradicional, especialmente retratos de los personajes principales, donde predomina un carácter sombrío (figs. 24, 25 y 26).
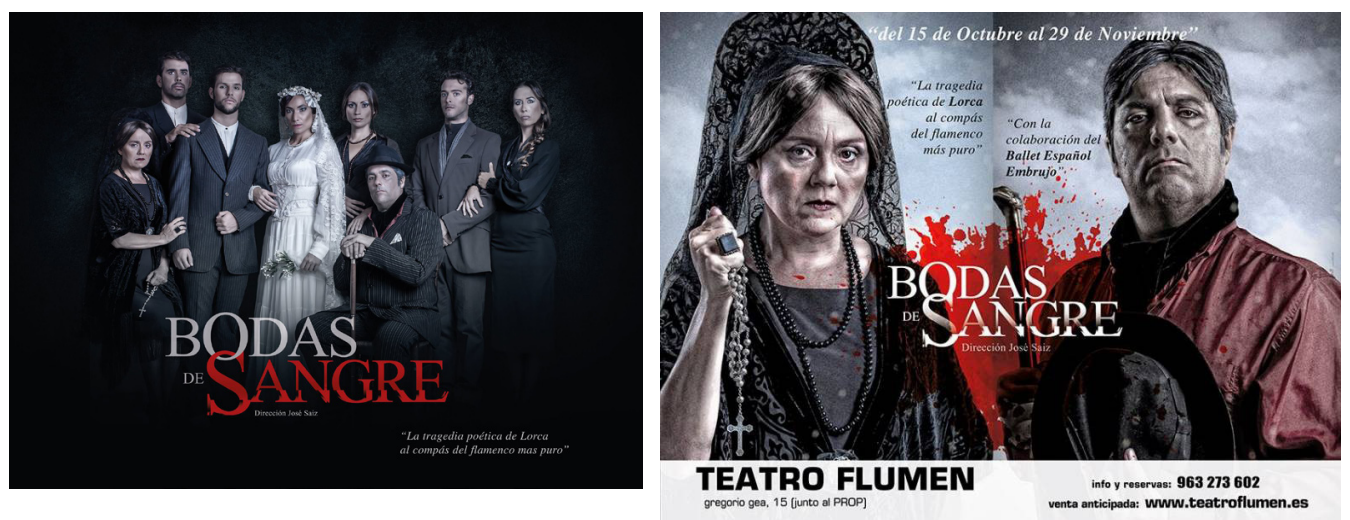

Figuras 24 y 25. Bodas de sangre en Teatro Flumen. Fuente: https://goo.gl/n7qg3J y https://goo. $\mathrm{gl} / \mathrm{b} 1 \mathrm{GhLK}$

Destaca también la presencia frecuente de símbolos clave, como el ramo de flores o el vestido de novia, así como las propias manchas de sangre que se insinúan en mayor o menor medida, bien sea de forma explícita como vemos en la figura 24 , como a través de la tipografía (figs. 25 y 26).

Estos tres carteles son de índole distinta aunque coincidan en el uso de la fotografía. De todos ellos quizás el más convencional a nivel conceptual, a pesar del tratamiento contemporáneo que se le ha dado a la fotografía, es el segundo (fig. 25), en el que vemos a todo el reparto como reclamo. Aparecen los actores y actrices dentro de sus personajes en una posición que 
si conocemos el texto nos puede dar algunas pistas sobre la obra. El anterior (fig. 24) que usa la imagen de dos de los personajes, también advierte de la trama mediante un tratamiento fotográfico más agresivo y superponiendo elementos gráficos como las manchas de sangre.

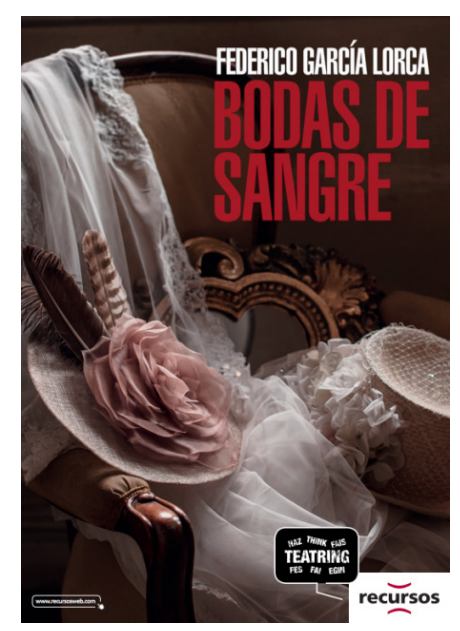

Figura 26. Bodas de sangre por Teatring

En contraposición a estos tenemos el tercero (fig. 26), que ya no usa una imagen de los protagonistas de la historia sino que apuesta por un retrato referencial en el que se ve el velo, un tocado de mujer, así como un canotier. La estética de los elementos, así como de la fotografía en conjunto, es otra de las diferencias respecto a los dos anteriores: por un lado porque los atuendos están enmarcados en la contemporaneidad — podrían pertenecer a cualquier boda actual—y

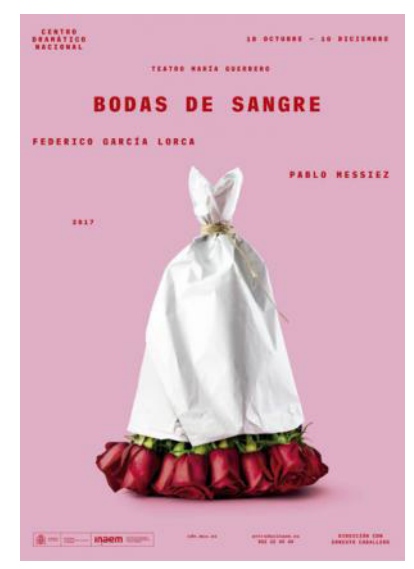

Figura 27.. Bodas de sangre Javier Jaén (2017). Fuente: Centro CDN. https://goo.gl/MevTNH

por otro porque, vistos en conjunto, dan a la imagen un carácter pastel que se contrasta de forma radical con la presencia de una tipografía contundente, impetuosa, sin serifas y de color rojo abrumador.

Y ya, lejos de todos ellos, tenemos la propuesta para el último montaje de Bodas de Sangre producida por el CDN y dirigida por Pablo Messiez en la temporada 2017-2018. El cartel fue a cargo de Javier Jaén y rompe con lo que habíamos visto hasta ahora en lo que refiere a este texto teatral. De entrada, lejos de los lúgubres grises y negros, Jaén en apuesta por un alegre fondo 
rosa que, desde la jovialidad del color en combinación con una serie de elementos visuales (como la fotografía del objeto y la tipografía) cuenta cómo en este montaje no se lanzará el ramo, no habrá una futura boda, vaticinando un fatal desenlace fruto de insanas pasiones. Y todo ello con esta imagen simple, limpia, pero a la vez discurrida y cargada de significado (fig. 27).

Si analizamos los diferentes elementos vemos, en primer lugar, lo que el ramo de novia sugiere: si en las ceremonias matrimoniales está asociado a los buenos augurios, en esta ocasión se presenta volteado, boca abajo, otorgando una connotación negativa cercana al mal presagio. Además, si nos fijamos, la forma que tiene el ramo es de vestido de novia — uso de la sinécdoque como forma retórica habitual en el cartelismo (Bouza, 1983) — ; un vestido de palabra de honor cuya cintura se consigue mediante un nudo que igualmente posee gran fuerza expresiva otorgando tensión al conjunto. Por último, la elección de las rosas rojas, que encajan perfectamente a la hora de describir este drama, teniendo en cuenta el valor simbólico de estas flores: están asociadas a la sexualidad femenina — desde el nacimiento a la menstruación o el alumbramiento—, siendo además las flores vinculadas al amor por antonomasia, a la pasión, la misma que llevó al trágico desenlace de la obra de Lorca.

Con ello lo que se pretende era trasladar al cartel la idea que el director de la obra, Messiez, tenía en mente: huir de la imagen clásica para hacer un montaje más arriesgado, con escenografías basadas en la abstracción pictórica del pintor Mark Rothko, un diseño de iluminación diferente, etc. y la imagen gráfica del cartel tenía que ir en consonancia. Por ello, una vez que el CDN hace el encargo a Javier Jaén, este, además de tener el texto habla con el director escénico para poder entender de primera mano las claves del discurso que tendrá que plasmar después en la imagen.

A partir de ahí elaboró tres propuestas diferentes de las cuales el CDN eligió una: la que aunaba el planteamiento simbólico con la contundencia expresiva que es ya marca CDN; pero también con ese punto lúdico que tiene el trabajo de Jaén y que dista mucho de los carteles que se habían hecho anteriormente para esta misma obra en el CDN — (figuras 28 y 29), igualmente
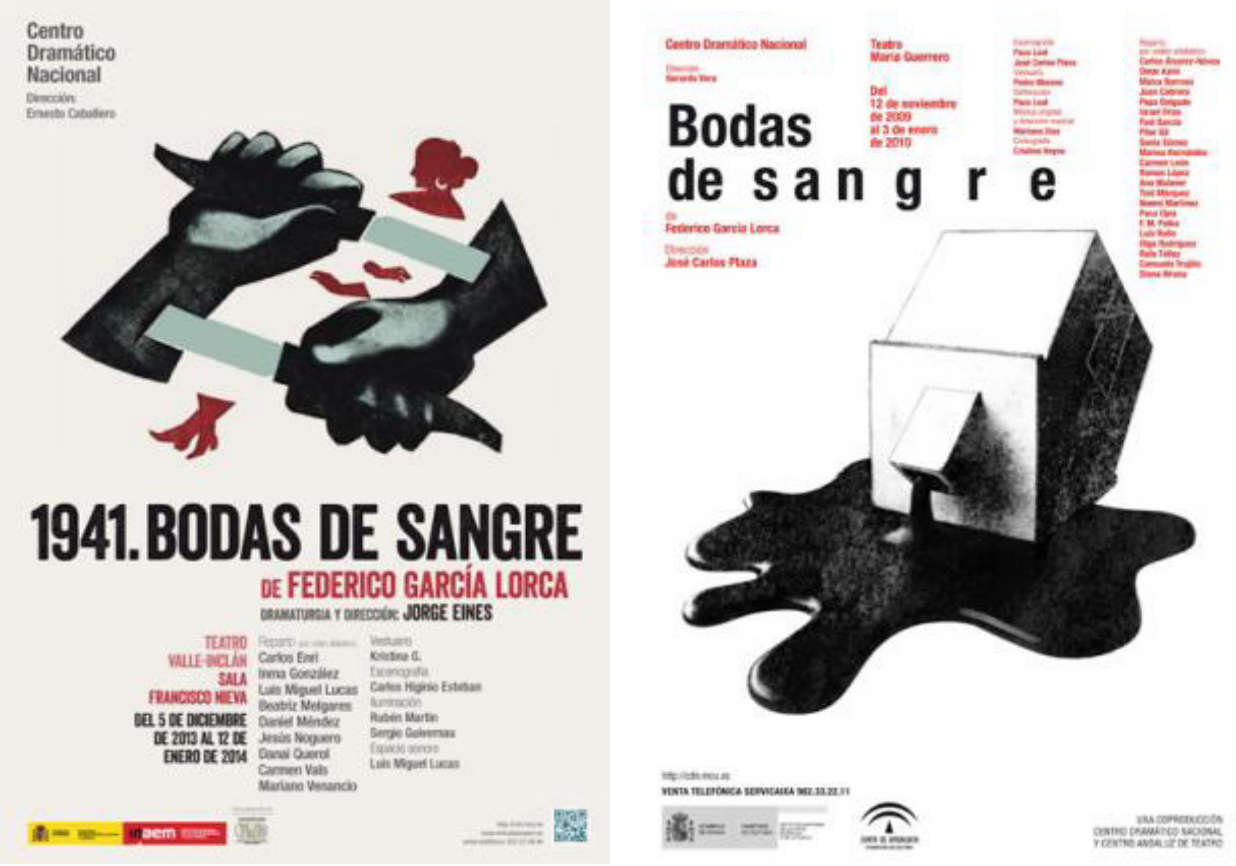

Figuras 28 y 29. Isidro Ferrer. Bodas de sangre (2009). Fuente: https://goo.gl/NrcbjH Bodas de sangre, Mar López y Riki Blanco (2013). Fuente: https://goo.gl/y2CbuL 
simbólicas pero jugando con colores (rojo, negro) y elementos visuales (relacionados con la muerte como el cuchillo o la sangre) más sabidos-.

\subsection{Análisis del uso fotográfico y resultados}

Para poder analizar la evolución de la cartelería producida por el CDN en los últimos años, ha sido necesario comparar el estilo visual y herramientas utilizadas en cada una de las temporadas. Para ello, a continuación organizamos en tablas los diferentes carteles indicando su temporada, autor y técnica (Tabla 1, 2, 3 y 4).

Tabla 1. Carteles del CDN. Temporadas 2005-2011

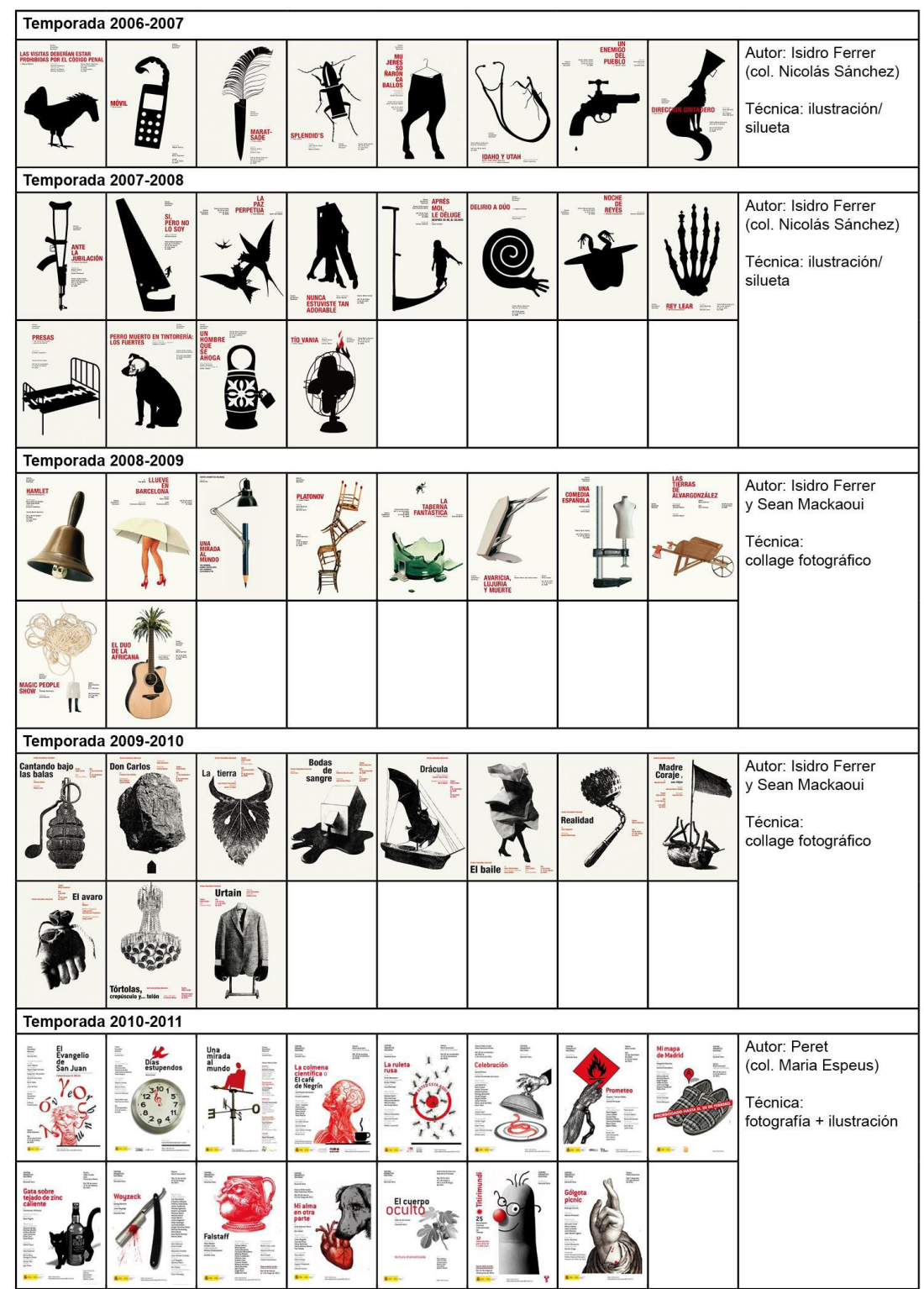


Tabla 2. Carteles del CDN. Temporadas 2011-2015

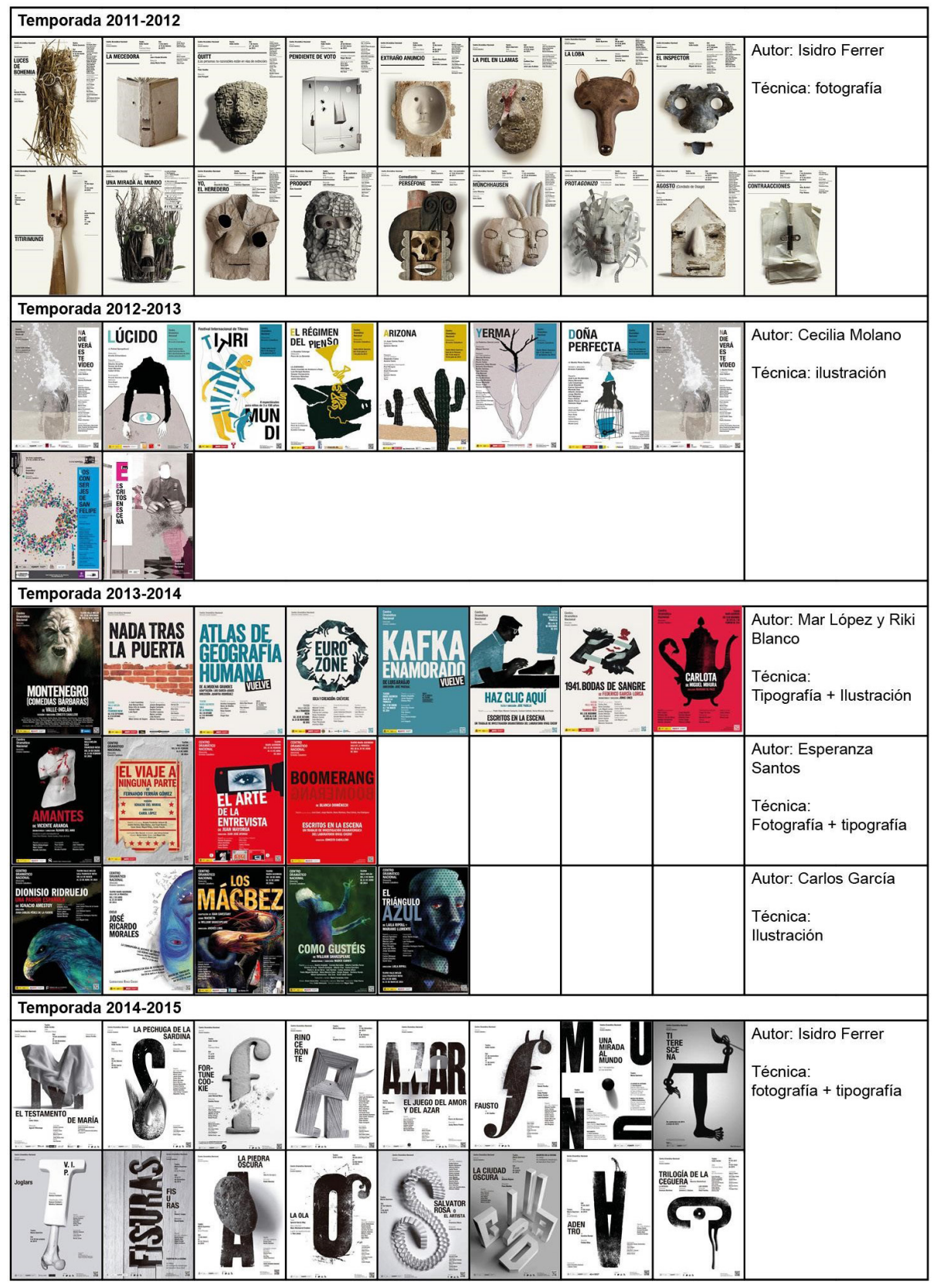


Tabla 3. Carteles del CDN. Temporadas 2004-2018

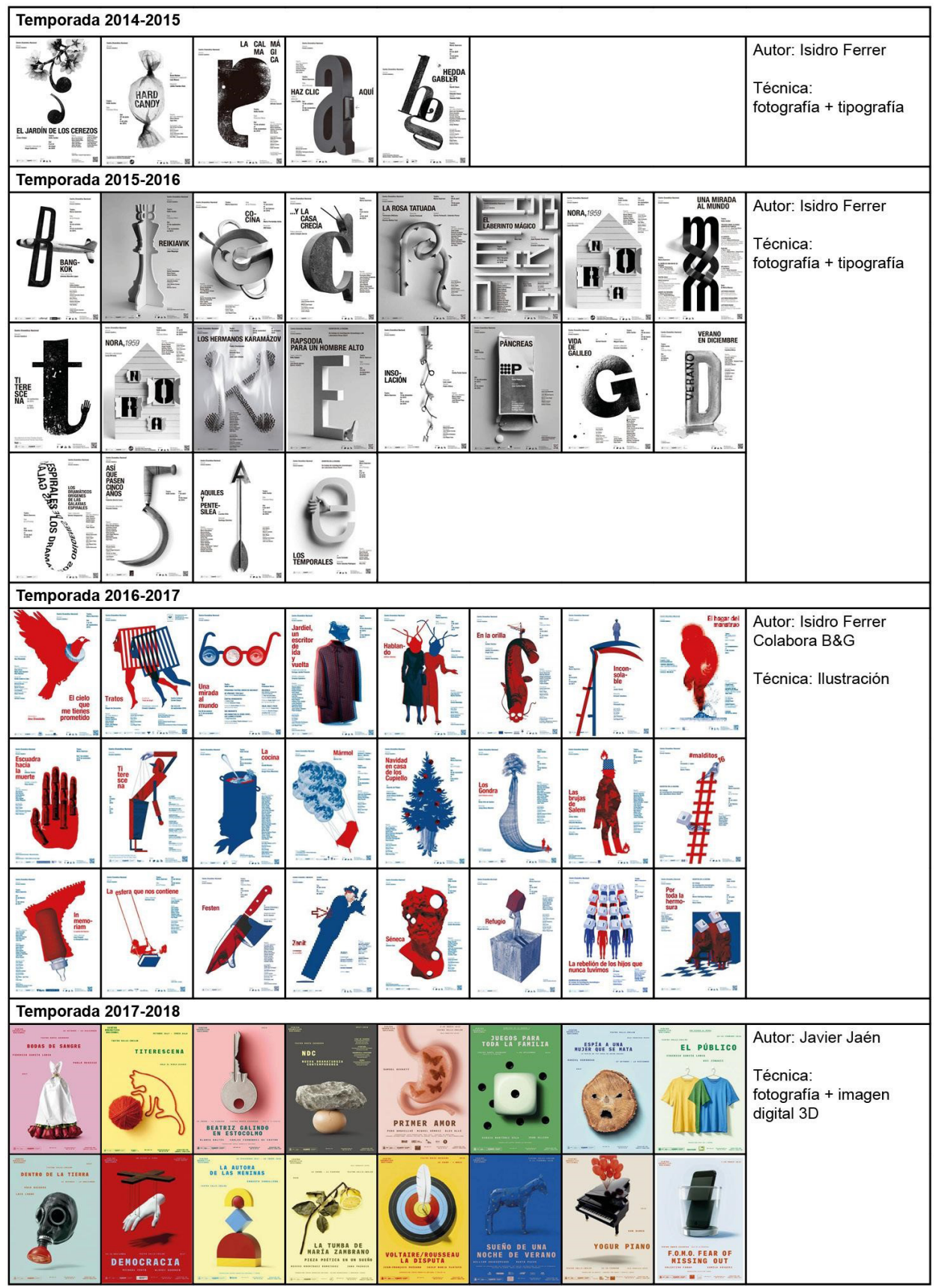


Tabla 4. Carteles del CDN. Temporadas 2017-2018

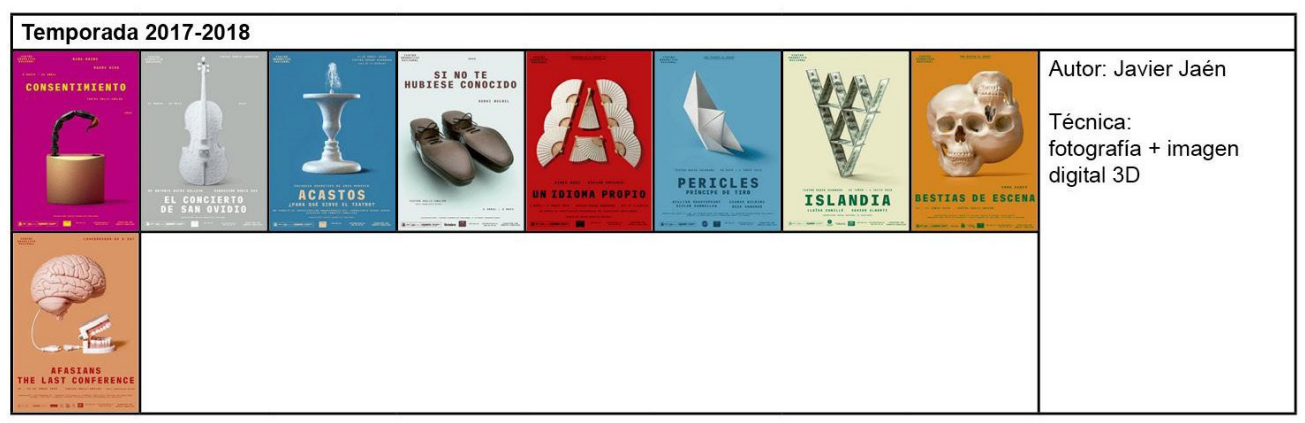

Tras haber inventariado y estudiado la evolución de los carteles del Centro Dramático Nacional durante los últimos doce años, podemos ver el peso que tiene la fotografía en relación con los que usan otro tipo de herramientas expresivas como base, como pueda ser el dibujo.

\section{Porcentaje de carteles fotográficos CDN 2006-2018}

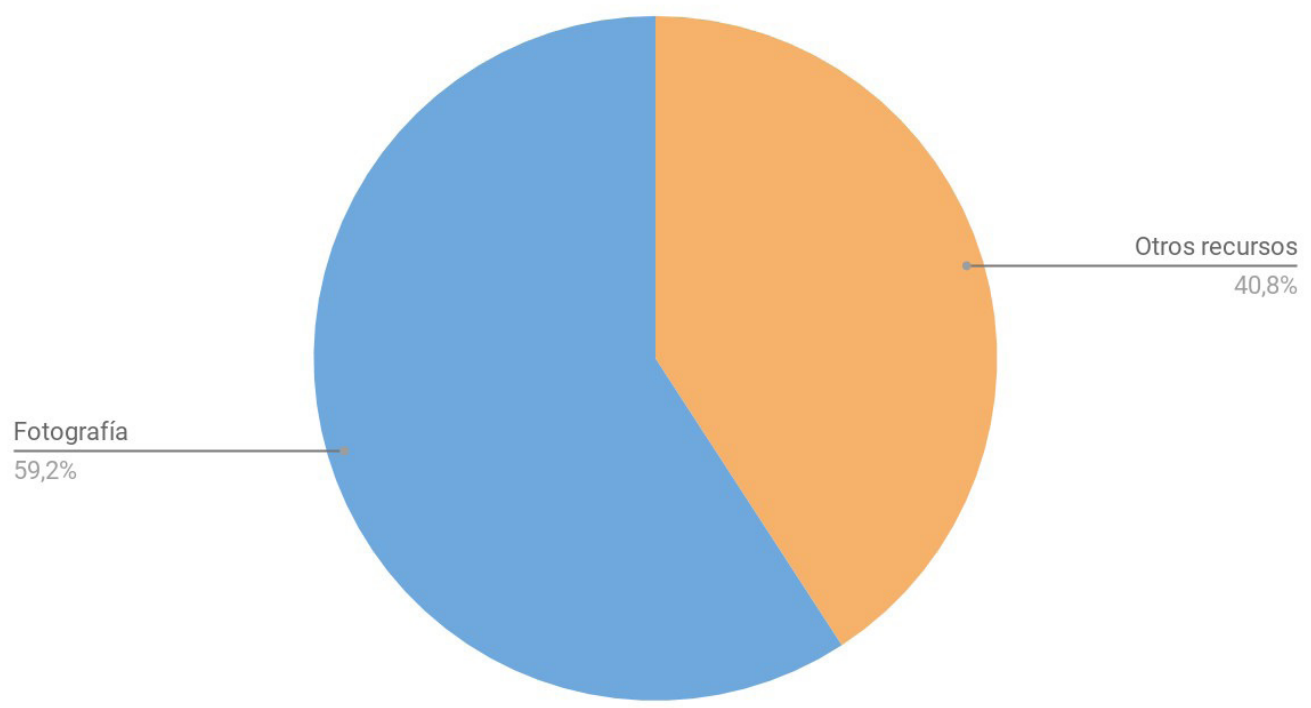

Figura 30. Relación entre carteles fotográficos y carteles que utilizan otros recursos. Fuente: Elaboración propia.

Una vez hemos discernido los carteles basados en la imagen fotográfica del resto - 59,2\% frente al 40,8 \% - los hemos organizado en función del tipo de fotografía, haciendo una clasificación basada en tres parámetros fundamentales:

- imagen apropiada.

- imagen construida a partir de la toma fotográfica.

- imagen generada mediante procedimiento digitales. 
Entendemos como imagen apropiada aquella ya existente que no hemos creado, sino que hemos encontrado en revistas, internet, mercadillos o archivos, ya sean éstos públicos o personales. Es un tipo de fotografía que se usa habitualmente para alterarla y resignificarla, tal y como hizo

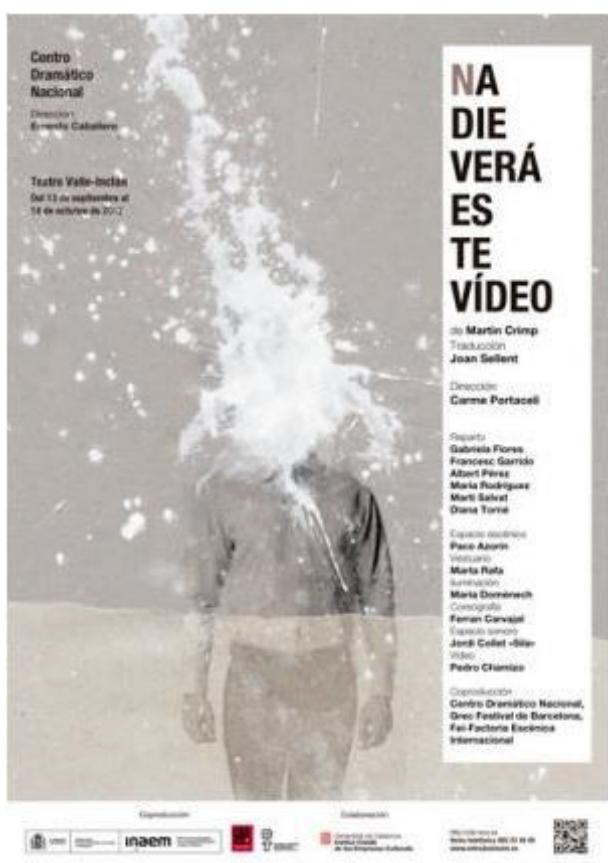

Figura 31. Cecilia Molano. Nadie verá este vídeo (2012). Fuente CDN: https://goo.gl/rRLvrG Cecilia Molano en el primero de los carteles que creó para el CDN (fig. 31).

La imagen construida a partir de la toma fotográfica sería la que el artista crea expresamente, para lo cual dispone de un set, una cámara fotográfica, la disposición de luz deseada y el objeto u objetos a retratar. En este sentido conviene apuntar que no siempre es el propio artista el que realiza la toma, pero sí el que construye la fotografía. Es decir, el que crea cómo será, a pesar de que sea un asistente el que haga la toma en sí misma — como ocurre con Isidro Ferrer, en cuyo trabajo no dispara él directamente, sino que es su hijo el que se encarga de este cometido-.

Es un dato que si bien en absoluto pone en duda la autoría o creatividad del creador del cartel, nos sirve para entender que el diseñador no ha de ser necesariamente fotógrafo, ni tener amplios conocimientos de la materia. Otro ejemplo es el citado Javier Jaén que en ocasiones cuenta también con asistentes, sobre todo en los casos en que trabaja con formatos fotográficos que requieren mayor grado de especialización técnica o un equipo particular y/o más complejo.

En esta categoría consideramos fundamentales los trabajos realizados por Isidro Ferrer en la temporada 2011-2012 (figura 32).
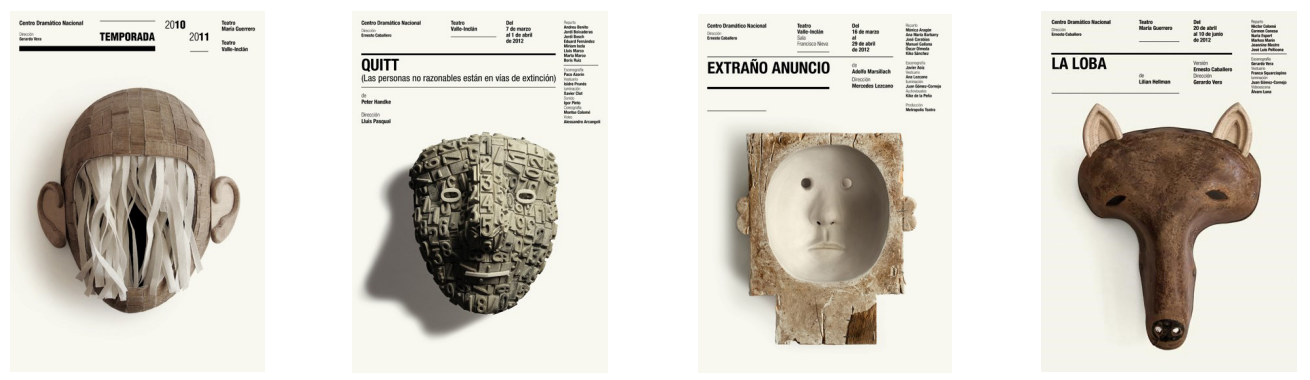

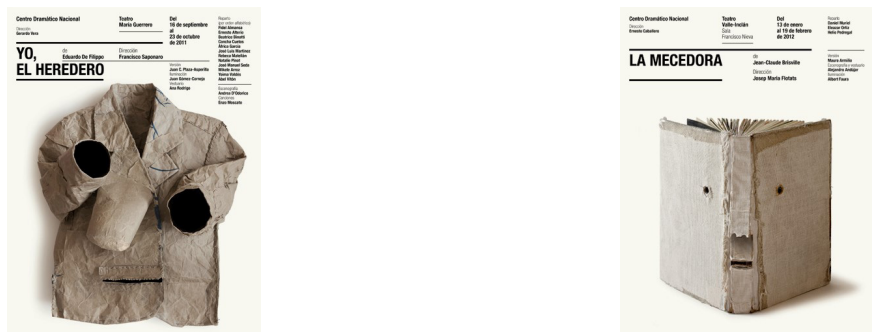

Figura 32. Isidro Ferrer. Selección de cartees de la temporada 2011-2012. Fuente: Isidro Ferrer, https://goo.gl/bQBYqF

Se trata de una serie de carteles de los que ya hemos hablado anteriormente, basados en juegos visuales a partir de fotografías construidas que juegan a ser en cierto modo ilustración; amables, ingeniosas y armónicas entre ellas no solo por la construcción de un objeto humanizado como elemento protagonista, sino también por la gama tonal o el tipo de materiales que se utilizan.

La buena acogida que tuvo este tipo de carteles hizo que en encargos posteriores utilizara un modo de proceder similar, tal y como vemos en los ejemplos recogidos de la figura 33 .
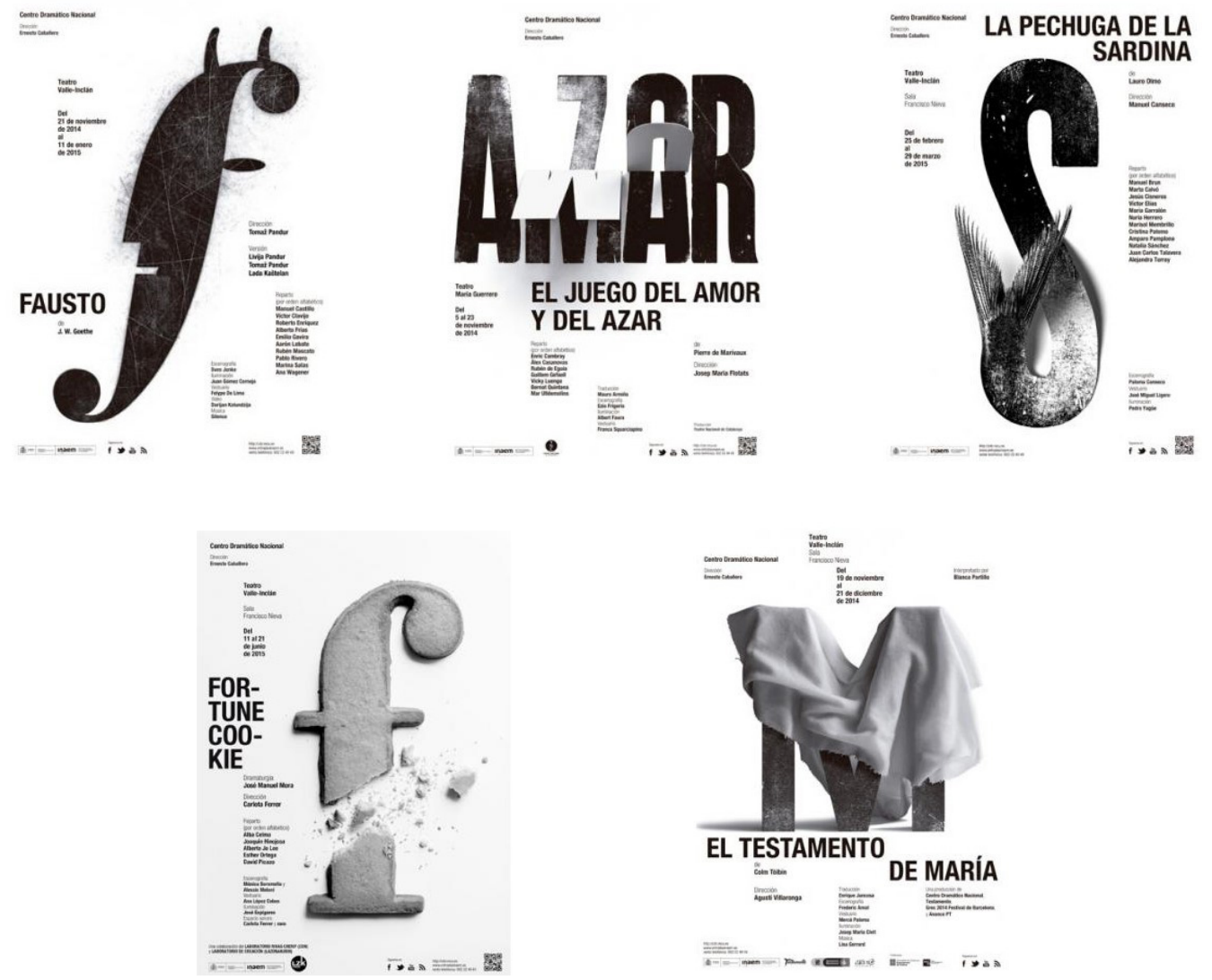

Figura 33. Isidro Ferrer. Selección de imágenes de la temporada 2014-2015. Fuente: Isidro Ferrer, https://goo.gl/bQBYqF 
La diferencia respecto a la selección anterior radica en que para esta temporada se basó en fuentes tipográficas que nuevamente construyó de forma artesanal y posteriormente fotografió. Algo que además pone en relieve la relación de la fotografía y el teatro con otras artes como la tipografía o el diseño.

La tercera clasificación es la de la imagen generada mediante procedimientos digitales. La hemos incluido como imagen fotográfica siendo conscientes de la controversia que esto puede generar. En la actualidad son ya muchos los fotógrafos cuyas imágenes no son sino imágenes sintéticas generadas en 3D de un realismo espectacular. El ámbito profesional con mayor empleo de esta técnica es sin duda el publicitario; es habitual que las fotografías que encontramos en catálogos y anuncios hayan sido generadas por ordenador, a pesar de lo cual siguen siendo fotografías. Sirvan de ejemplo las figuras 34 y 35 .
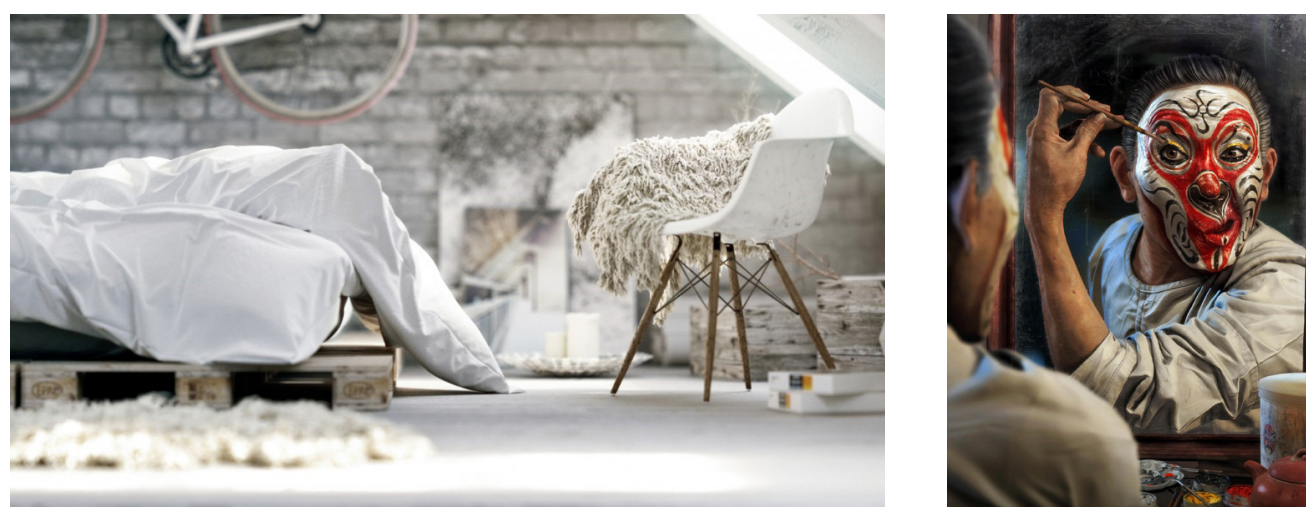

Figura 34 Atelier Feuerroth. Imagen sintética creada por renderización 3D. Autor: Michael

Feuerroth. Fuente: http://feuerroth.de/. Figura 35 Zhong Wei Long. Imagen sintética creada mediante el software Zbrush sculpting. Fuente: https://goo.gl/Gr5Dv6

Ambas impactan por su realismo fotográfico, por lo que hemos decidido apostar por esta clasificación en la que hemos incluido el cartel de Javier Jaén para el montaje Beatriz Galindo en Estocolmo (2018); en el que nuevamente el artista juega con el objeto alterándolo para que muestre, además de la llave, la silueta de una cara de mujer — como ya hizo en el vestido de novia y el ramo de flores invertido de Bodas de Sangre- Inicialmente pensamos que se trataba de una manipulación artesanal, pero fue él mismo el que nos reveló que se trataba de una imagen digital.

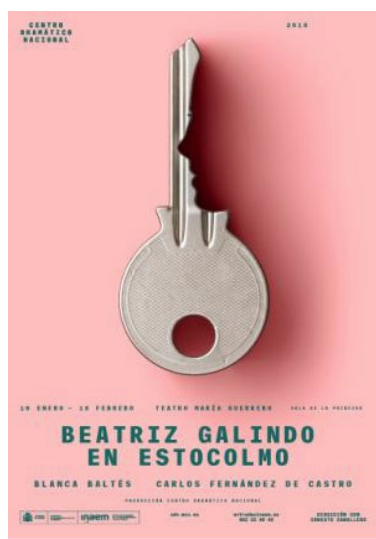

Figura 36. Javier Jaén. Beatriz Galindo en Estocolmo (2018). Fuente: https://goo.gl/5xYD5y 


\section{Conclusiones}

El Centro Dramático Nacional posee una amplia representación de cartelería basada en la fotografía artística, donde el ingenio sirve de herramienta fundamental para representar sus montajes teatrales. Tomando el CDN como caso de estudio y analizando su trayectoria hemos podido repensar la imagen fotográfica aprovechando su función persuasiva. En este sentido, pudimos observar que — contrariamente a lo que inicialmente pensábamosla fotografía en los carteles del CDN, a pesar de configurar propuestas sugerentes y significantes, no funciona como como el eje central y supremo, sino que se trata de una herramienta de expresión a combinar con otras no menos importantes como el dibujo o el uso de las tipografías. Esto mismo fue además ratificado por los creadores a los que entrevistamos.

Esto no resta importancia a la fotografía sino que en este tipo de trabajos — de igual forma que ocurre con los montajes teatrales-, el CDN aboga por que haya un trabajo colaborativo entre las diferentes artes de forma que todas contribuyan al resultado final, sin hegemonías. Así pues, la fotografía aquí está al servicio del mensaje del cartel, lo cual pone de manifiesto la flexibilidad de la fotografía para integrarse en diferentes entornos y ser combinada con recursos propios del diseño gráfico (tipografía, ilustración, etc.). De este modo la fotografía resulta una herramienta comunicativa más, estando su tratamiento relacionado con el texto teatral, el mensaje a transmitir y las emociones a sugerir.

En este contexto, el fotógrafo/diseñador/creador tiene un papel muy importante por cuanto se convierte en una especie de dramaturgo gráfico. Para justificarlo definimos el teatro como un espacio de ficción dentro de la realidad. Partiendo de tal premisa y en palabras de Jaén, "en el teatro podemos dar vida a objetos inmateriales, crear pequeños imposibles; se cuentan pequeñas mentiras que explican grandes verdades, lo mismo que ocurre en los carteles de los diferentes montajes" (Jaén, 2017). Atendiendo a ello, los carteles son todo un mundo creado por el artista; pero sin dejar de lado su dependencia del texto y del montaje teatral, en un intento de transmitir visualmente los puntos clave de la obra junto con otros recursos expresivos.

En relación al CDN esta mezcolanza de disciplinas en la conformación del cartel ha sido un acierto en opinión de la propia institución. Tal afirmación no se fundamenta en cifras de taquilla ya que hasta el momento no se ha hecho un estudio sobre la relación directa de éstas con los carteles de promoción - y no hemos tenido acceso a los datos necesarios para poder llevarlo a cabo- . Además, la recaudación de cada montaje va ligada a muchos otros factores de índole muy diversa — tales como el momento del mes en que se estrene, la temporada del año o la programación alternativa - con lo que no podrían estudiarse todos los carteles atendiendo a los mismos parámetros, ni se obtendrían datos contundentes y fidedignos.

En definitiva - y en consonancia por las declaraciones del director del CDN- nos limitamos a afirmar que, independientemente del aumento en taquilla que hayan podido generar, los carteles del CDN hoy por hoy — y especialmente desde el 2006 con la apuesta que se hizo al encargarlos a diseñadores profesionales y artistas visuales-, son un signo 
de identidad fundamental de la institución, potenciando la conexión de esta con su público objetivo que valora, entiende y disfruta de ellos.

\section{Bibliografía}

Álvarez del Vayo (2017). Cómo ha cambiado la venta de smartphones en los últimos años. El Español (30/3/2017). Disponible en: https://goo.gl/EGKueg

Barnicoat, J. (2000) (primera edición, 1972). Los carteles: Su historia y lenguaje. Barcelona: Gustavo Gili.

Bouza Álvarez, F. (1983). Procedimientos retóricos del cartel. Madrid: Centro de Investigaciones Sociológicas.

Caballero, Ernesto (2017). Entrevista personal realizada por teléfono el 13 de marzo de 2017.

Calatrava, Guillem (2013) En España se comparten 5,7 millones de fotografías al día. Naturpixel. com (3/07/2013). Disponible en: https://goo.gl/rML7Jd

de la Calle, R. (2013). Crear imágenes / fingir objetos. Diálogos entre las propuestas artísticas de Isidro Ferrer, Sean Mackaoui y Chema Madoz. EME Experimental Illustration, Art \& Design, 1(1), 52-61. DOI: https://doi.org/10.4995/eme.2012.1777

Díaz de Tuesta, M. J. (2008) Carteles con una historia detrás. Isidro Ferrer pone la ilustración al servicio de la literatura y el teatro. El País (25/3/2008). Disponible en: https://goo.gl/Pfaz2L

Enel, François (1977). El cartel. Lenguaje, funciones, retórica. Valencia: Fernando Torres.

Foster, J. (2006): Carteles. Nuevos diseñadores. Barcelona: Gustavo Gili.

Gómez Gómez, A. (2009) El postcartel en la era digital. En Actas del I Congreso Internacional Latina de Comunicación Social. Tenerife: Sociedad Latina de Comunicación Social. Disponible en: https://goo.gl/beZKEe

Heras, D. (2012). Incidencia de los medios de reproducción en la evolución de la ilustración gráfica. Tesis doctoral publicada. Valencia: Universitat Politècnica de València. Disponible en: https://goo. gl/f7DPSA

Jaén, Javier (2017). Entrevista personal realizada por teléfono el 13 de marzo de 2017.

Molano, Cecilia (2017). Entrevista personal realizada por Skype el 7 de marzo 2017.

Osuna, C. (2011) Diseño gráfico, lo tuyo es puro cartel. Duendemad.com [recurso en línea] Disponible en: https://goo.gl/PfZuQD

Photoworld (2015). If you were to shared on Snapchat in the last hour how long would it take?. Disponible en: https://goo.gl/WLMuWr 
MHCJ no 9 (2) | Año 2018 - Artículo no 11 (126) - Páginas 309 a 336 - mhjournal.org

Renau, J. (1976). Función social del cartel publicitario. Valencia: Fernando Torres.

Tomás, F. (2006). Guerra civil española y carteles de propaganda: el arte y las masas. Olivar, 7(8), 63-85. Disponible en: https://goo.gl/tFSZws

Zenith Media (2015). ¿Qué es y cómo funciona la publicidad de alto impacto?. Zenith Media (28/8/2015). Disponible en: https://goo.gl/UCWX9j 
MHCJ no 9 (2) | Año 2018 - Artículo no 11 (126) - Páginas 309 a 336 - mhjournal.org

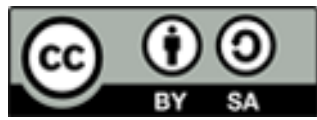

Licencia Creative Commons

Miguel Hernández Communication Journal

mhjournal.org

\section{Cómo citar este texto:}

Sandra Martorell Fernández, Álvaro Sanchís Gandía (2018): La fotografía artística contemporánea en el marco de la promoción cultural. Los carteles del Centro Dramático Nacional como caso de estudio, en Miguel Hernández Communication Journal, nº9 (2), pp. 309 a 336. Universidad Miguel Hernández, UMH (Elche-Alicante). DOI: http://dx.doi.org/10.21134/mhcj.v0i9.259 